\title{
Astrocytes: Heterogeneous and Dynamic Phenotypes in Neurodegeneration and Innate Immunity
}

The Neuroscientist

$1-20$

(C) The Author(s) 2018

Article reuse guidelines:

sagepub.com/journals-permissions DOI: $10.1177 / 107385841880994$ journals.sagepub.com/home/nro

(S)AGE

\author{
Colm Cunningham ${ }^{\prime}(\mathbb{D})$, Aisling Dunne ${ }^{1,2}$, and Ana Belen Lopez-Rodriguez'
}

\begin{abstract}
Astrocytes are the most numerous cell type in the brain and perform several essential functions in supporting neuronal metabolism and actively participating in neural circuit and behavioral function. They also have essential roles as innate immune cells in responding to local neuropathology, and the manner in which they respond to brain injury and degeneration is the subject of increasing attention in neuroscience. Although activated astrocytes have long been thought of as a relatively homogenous population, which alter their phenotype in a relatively stereotyped way upon central nervous system injury, the last decade has revealed substantial heterogeneity in the basal state and significant heterogeneity of phenotype during reactive astrocytosis. Thus, phenotypic diversity occurs at two distinct levels: that determined by regionality and development and that determined by temporally dynamic changes to the environment of astrocytes during pathology. These inflammatory and pathological states shape the phenotype of these cells, with different consequences for destruction or recovery of the local tissue, and thus elucidating these phenotypic changes has significant therapeutic implications. In this review, we will focus on the phenotypic heterogeneity of astrocytes in health and disease and their propensity to change that phenotype upon subsequent stimuli.
\end{abstract}

\section{Keywords}

astrocyte, heterogeneity, priming, phenotype, chemokine, chronic neurodegeneration

\section{Introduction}

Although the important role of astrocytes in supporting neuronal function has been known for many years and continues to be elucidated, information on their roles in responding to local neuropathology and in the mediation of innate immune responses has rapidly expanded in recent years. Moreover, although astrocytes have largely been researched with an apparent assumption about homogeneity of phenotype, it is now apparent that they show considerable phenotypic diversity, influenced by their regional environment within the brain and by dynamic changes to that environment arising during pathology, stress, or inflammation. In this review, we will focus on the phenotypic heterogeneity of astrocytes in health and disease and their propensity to change that phenotype upon subsequent stimuli. It is not possible to address all studies on astrocytes in pathology here, and we refer readers to excellent reviews on astrocytes in the normal and pathological brain (Sofroniew and Vinters 2010; Verkhratsky and Nedergaard 2018). To understand how astrocyte function shapes function and dysfunction in the brain it is important to recognize that phenotypic diversity occurs at two quite different levels: that determined by regionality and development and that determined by dynamic changes to the environment of astrocytes during pathology.

\section{A Brief History of Astrocytes}

Rudolph Virchow first introduced the idea of "neuroglia," defining it as "nerve glue," the connective substance in which nervous system elements are embedded and which contains a number of cellular elements (Virchow 1858).

\footnotetext{
'School of Biochemistry and Immunology, Trinity Biomedical Sciences Institute and Trinity College Institute of Neuroscience, Trinity College, Dublin, Republic of Ireland

${ }^{2}$ School of Medicine, Trinity Biomedical Sciences Institute and Trinity College Institute of Neuroscience, Trinity College, Dublin, Republic of Ireland
}

\section{Corresponding Author:}

Colm Cunningham, School of Biochemistry and Immunology, Trinity Biomedical Sciences Institute, Trinity College, Dublin, D2, Republic of Ireland.

Email: colm.cunningham@tcd.ie 
Years later, Camilo Golgi described cells with some of the typical characteristics of astrocytes and demonstrated the existence of glial-vascular contacts (endfeet) using the silver nitrate stain, developed in 1873, and at it was at the end of the century when the idea of a close interaction between neurons and glia was suggested (Schleich 1894). Santiago Ramón y Cajal applied the Golgi method to describe almost every part of the central nervous system (CNS), including astrocyte morphology, but lamented the lack of tools available to study these cells (Ramón y Cajal 1995). As early as 1893, astrocytes were classified into two different categories: fibrous and protoplasmic (Andriezen 1893; Kölliker 1889). Broadly speaking, protoplasmic astrocytes are long, unbranched, mostly present in the grey matter, $\mathrm{S} 100 \beta$ positive, with low or absent glial fibrillary acidic protein (GFAP) and involved in the "neurovascular unit," whereas fibrous are defined as short, with highly branched processes, located in the white matter, GFAP-positive, and probably related to myelination processes (Chaboub and Deneen 2012). Transcriptomic analysis identified several differences between GFAP positive $(\mathrm{GFAP}+)$ and GFAP negative (GFAP-) astrocytes from the normal mouse brain, but many of these genes were not astrocyte specific, and generally speaking, their profiles were markedly similar (Lovatt and others 2007). These two phenotypes have been the main descriptors for decades. However, recent works show that the distribution and proportion of these two astrocyte types varies across brain regions (Emsley and Macklis 2006) with up to nine different astrocyte morphologies in the brain including protoplasmic and fibrous astrocytes but also tanycytes and radial, Bergmann, Muller, velate, marginal, and perivascular glia. However, although Bergmann and Muller glia are morphologically different to protoplasmic astrocytes, they have similar functions in the adult brain with respect to the regulation of synaptic activity (Bringmann and others 2009; Hoogland and Kuhn 2010). Therefore, the categorization of astroglia based on gross morphology is not enough to establish clearly differentiated functional groups of astrocytes. The analysis of molecular profiles is obviously necessary.

\section{Molecular Heterogeneity}

The analysis of astrocyte-rich cultures and CNS tissue homogenates began to elucidate the molecular profile of astrocytes (Bachoo and others 2004; Doyle and others 2008) showing that in vitro astrocytes cultured in serumcontaining media show significant activation compared to astrocytes isolated ex vivo (Cahoy and others 2008). Another key difference is Notch signaling and its target genes Hes 5 and Hey2, which are (a) induced by rat neurons co-cultured with mouse astrocytes, (b) are repressed when astrocytes are removed from their in vivo environment, and (c) are induced again when neurons are overlaid onto ex vivo astrocytes (Hasel and others 2017). Significant differences are apparent among astrocytes, governed by their position on the dorsoventral axis (Morel and others 2017), possibly driven by dorsoventral gradients of organizing signals such as Sonic hedgehog (Farmer and others 2016). A highly detailed comparison of striatal and hippocampal astrocytes revealed significant differences in morphology, in electrophysiological properties, in $\mathrm{Ca}^{2+}$-signaling, and in synaptic proximity, suggesting a specialization of astrocytes within different neural circuits (Chai and others 2017). Recent single cell RNA sequencing studies have identified seven discrete molecular phenotypes for astrocytes in the mouse brain (Zeisel and others 2018), with an obvious distinction between telencephalon and non-telencephalon astrocytes, which appears developmentally determined. Even within these two broad regions, each show two discrete populations based on their Gfap expression and these appear to correspond to fibrous and protoplasmic astrocytes from each region. Astrocytes originate from the neuroepithelium-derived radial glia (Kriegstein and Alvarez-Buylla 2009) around the embryonic day E16-18, when the CNS development switches from neurogenic to gliogenic (Deneen and others 2006), and they reach their "mature gene profile" at P30 (Cahoy and others 2008). While the specific region where astrocytes are born confers, on them, a morphological and functional heterogeneity, cell fate tracking techniques and modifications of the "brainbow" method show that even different astrocyte populations within the same brain region show heterogeneity that is determined early in development (Bribián and others 2016).

\section{Function of Astrocytes in the Healthy Brain}

The functions of astrocytes are varied and many and consequently astrocytes are competent communicating elements within the CNS (Fig. 1). Astrocytes communicate with each other mainly through connexin 43-containing gap junctions, resulting in a functionally coupled "glial syncytium" that allows the rapid transfer of ions, ATP, glucose, cAMP, $\mathrm{IP}_{3}$, amino acids, and gliotransmitters such as GABA or glutamate (Orellana and Stehberg 2014). Astrocytes also communicate with microglia in health and disease, and although information on physical contacts between these cells is absent, there is an exchange of ATP, trophic factors, and amino acids that involves extracellular vesicles (Paolicelli and others 2018), P2Y receptors (Quintas and others 2018), or aquaporin-4 (Sun and others 2016).

Astrocytes maintain intimate communication with the cerebral vasculature through astrocytic "endfeet," forming the neurovascular unit that regulates the cerebral blood 


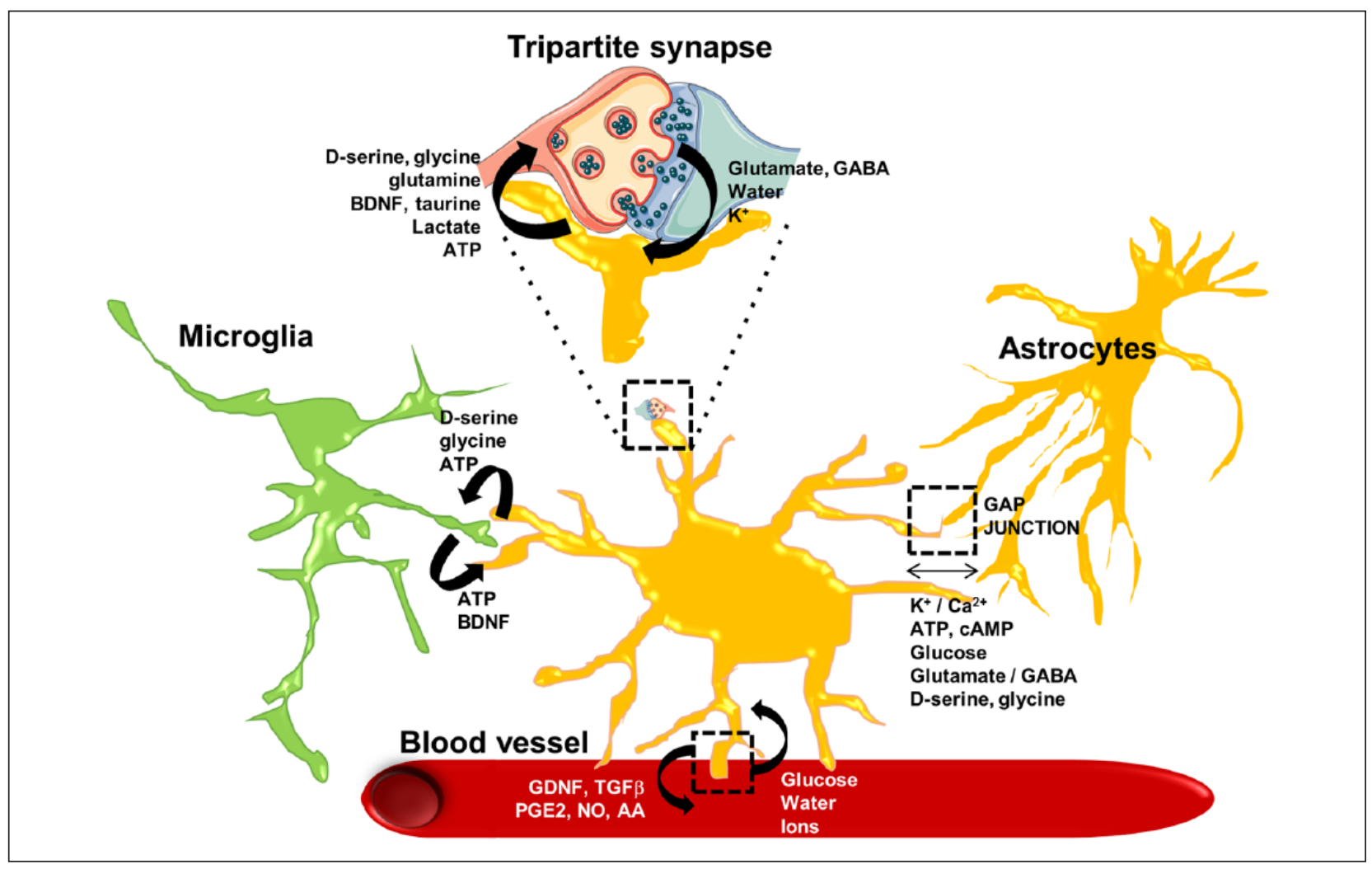

Figure I. Astrocyte function in the healthy brain. The role of astrocytes as communicating elements of the CNS, showing the interactions with the blood vessels, microglia, neurons, and neighboring astrocytes. GDNF = glial cell-derived neurotrophic factor; TGF $\beta=$ transforming growth factor beta; PGE2 = prostaglandin E2; NO = nitric oxide; AA = arachidonic acid; ATP = adenosine triphosphate; $\mathrm{CAMP}=$ cyclic adenosine monophosphate; BDNF = brain-derived neurotrophic factor.

flow $(\mathrm{CBF})$ and regulates the blood-brain barrier $(\mathrm{BBB})$ (Abbott 2002). Neuronal activity increases CBF and oxygen utilization at a local level in a process known as functional hyperemia. This is the basis of the BOLD signal measured in functional magnetic resonance imaging (fMRI) that allows us to image local changes in brain function in vivo (Chaigneau and others 2003). During synaptic activation, glutamate is released into the synaptic cleft and binds to the postsynaptic receptors inducing nitric oxide (NO) and prostaglandin (PG) release that contributes to vessel dilation. However, astrocytes also contribute to dilation and constriction of vessels via glutamate binding of astrocyte metabotropic glutamate receptors (mGluR) and release of vasoactive arachidonic acid (AA) and AA-metabolites. The complexities of CBF regulation are reviewed elsewhere (MacVicar and Newman 2015).

Neuronal energy metabolism is also influenced by astrocytes, not least because they are the only CNS cell type with glycogen stores. The conventional neuroenergetic hypothesis posits that glucose is the key energy source for neurons during neural activity and that the lactate produced during activity is removed after this process (Sokoloff 1989). The more recent astrocyte-neuron lactate shuttle hypothesis (Magistretti and Pellerin 1996) proposes that increased neuronal activity leads to increased astrocyte glucose uptake from the vasculature, preferential glycolysis in astrocytes, and increased lactate release to the milieu to be taken up and oxidized by neurons. Cortical astrocytes have been shown, ex vivo, to preferentially synthesize lactate from pyruvate and release lactate into the media, while neurons were 8-fold more likely to express lactate dehydrogenase (LDH) to synthesize pyruvate from lactate (Lovatt and others 2007). Furthermore, the existence of a lactate gradient from astrocyte to neurons has been shown using a genetically encoded lactate biosensor (Mächler and others 2016). However, it remains true that neurons have the capacity to use glucose in glycolysis: in vitro neurons have higher glucose analogue uptake rate than astrocytes and this is replicated in awake mice (Lundgaard and others 2015). There is clearly empirical support for both positions (Chih and Roberts 2003; Tang 2018). It is perhaps predictable that neurons would require metabolic versatility, also using fatty acids and ketone bodies for fuel, but astrocytes are important contributors to maintaining neuronal energy balance. 
Most synapses are surrounded by astrocytic processes, supporting the idea that astrocytes have important roles at the synapse. This "tripartite synapse," consisting of presynaptic and postsynaptic nerve terminals and the associated astrocyte, was first interrogated and named by Araque (Araque and others 1999). This concept evolved to include microglia and extracellular matrix in the "multipartite synapse" (Verkhratsky and Nedergaard 2014). The concept of the tripartite synapse embraces the important role of astrocyte glutamate transporters in the reuptake of synaptic glutamate and $\mathrm{K}^{+}$clearance by excitatory amino acid transporter 1 (EAAT1) and Kir4.1, respectively, but also considers the astrocyte expression of neurotransmitter receptors coupled to second-messenger systems that induce calcium waves and the release of "gliotransmitters" from astrocytes (glutamate, D-serine, ATP). These gliotransmitters have roles in regulating neuronal development, neurotransmitter release, and behavior (Halassa and Haydon 2010).

Astrocytes, therefore, are active players in neuronal communication, and given their heterogeneity, it might follow that specific astrocyte populations function differently in distinct neuronal circuits to modulate behavior. This was first demonstrated in sleep modulation studies. Sleep/wake states are regulated by adenosine levels via adenosine 1 (A1) receptors. Dominant negative SNARE mice, in which the vesicular machinery needed for neurotransmitter release is selectively disrupted in astrocytes, showed impaired adenosine release and disruptions in slow-wave activity during sleep (Halassa and others 2009). A specialized role of astrocytes in feeding behavior was demonstrated by postnatal ablation of insulin receptors in GFAP + cells. This manipulation changed the morphology, mitochondrial function, and circuit connectivity of hypothalamic astrocytes and lead to reduced activity in pro-opio-melanocortin hypothalamic neurons, and altered blood glucose and appetite (García-Cáceres and others 2016). Thus, in the healthy brain astrocytes serve as communicating elements, energy suppliers, and regulators of synaptic and behavioral function in specific ways that are underpinned by their basal heterogeneity (Ben Haim and Rowitch 2017; Oliveira and others 2015).

\section{Astrocytes as Innate Immune Cells}

Astrocytes fulfil an important role as innate immune cells in the brain. Innate immunity concerns the tissue's primary response to infection or injury and requires that local cells secrete inflammatory mediators such as cytokines, chemokines, and prostaglandins that initiate chemotaxis and control inflammatory cell infiltration and that these cells participate in removal of debris or microorganisms by phagocytosis. While there is substantial evidence that microglia are primary drivers of innate immune responses to disturbances within the CNS, it is clear that astrocytes express at least a subset of pattern recognition receptors (Farina and others 2007) and contribute to mediating the local innate immune response triggered by different stimuli or brain damage and their phenotype is heavily influenced by inflammatory cytokines (John and others 2005). Some facets of astrocyte contribution to innate immunity are detailed below, while their overlap with phenotypic diversity requires that some themes are revisited in later sections of this review.

\section{Pattern Recognition Receptors in Astrocytes: Bacterial Endotoxin}

Although many studies in the literature describe the response of astrocytes to LPS, most of those cultures "accepted" a residual microglial population of between $1 \%$ and $10 \%$, which are sufficient for mediating proinflammatory responses of these cultures to LPS (Saura 2007). Holm and colleagues rigorously purified astrocytes to determine their capacity for autonomous TLR responses, in absence of microglia. Using both flow cytometry and a myeloid lineage-specific suicide gene to demonstrably purify astrocytes from mixed glial cultures, these authors measured astrocyte responses to TLR agonists and showed that the response to TLR4 agonists was completely dependent on the presence of functional microglia (Holm and others 2012). The response of astrocytes to TLR2 and TLR3 agonists was also significantly less efficient in the absence of microglia and this raises a significant caveat to many studies in the in vitro literature. In the case of the TLR4 response to lipopolysaccharide, microglia exert their effect on astrocytes at least partially through release of soluble mediators that directly activate or facilitate astrocyte responses (Holm and others 2012), and LPS applied directly to purified astrocytes also had very limited effects on astrocyte phenotype in more recent studies (Liddelow and others 2017). These findings are consistent with our own observations: intracerebral challenge with LPS triggers the microglia to rapidly synthesize IL-1 $\beta$, but if this step is by-passed, and the cytokines IL- $1 \beta$ or TNF- $\alpha$ are directly applied to the hippocampus, the astrocyte population rapidly translocates NFKB to the nucleus and synthesizes chemokines CCL2, CXCL1, and CXCL10 (Hennessy and others 2015; Lopez-Rodriguez and others 2018). Thus, although influence can be exerted in either direction, it is likely that the microglial cell remains the primary responder to PAMPS and alarmins in most cases and that microglia secrete soluble mediators to drive astrocyte responses.

\section{Nucleic Acid Sensing by Astrocytes}

One set of responses that is very robust in astrocytes is orchestrated by nucleic acids sensors. In addition to detecting double stranded (ds) RNA in endosomal 
compartments via TLR3, astrocytes can sense cytosolic RNA via the Rig-I-Like Receptor (RLR) proteins, retinoic acid-inducible gene I (RIG-1), and melanoma differentiation-associated protein 5 (MDA-5) (De Miranda and others 2008; Furr and others 2008). These receptors signal through the mitochondrial protein, mitochondria antiviral-signaling protein (MAVS), and the kinases, ІкB kinase- $\varepsilon(\mathrm{IKK} \varepsilon)$ and TANK-binding kinase-1 (TBK-1), to drive interferon regulatory factor (IRF) activation and subsequent type 1 interferon production (Chow and others 2018). Astrocytes have also been reported to express the endosomal receptors, TLR7 and TLR9, which detect single stranded viral RNA and bacterial unmethylated CpG DNA, respectively (Butchi and others 2010). In addition to endosomal DNA detection, we have demonstrated that highly purified murine astrocytes express a number of putative DNA binding PHYIN proteins (so called as they contain an N-terminal PYRIN domain and a C-terminal HIN domain) and the enzyme cyclic GMPAMP synthase (cGAS) and respond robustly to cytosolic DNA via cGAS and p204 (Cox and others 2015). Upon binding dsDNA, cGAS converts ATP and GTP to 2'5'cGAMP, a cyclic di-nucleotide second messenger, which subsequently binds the ER-membrane bound protein, stimulator of interferon genes (STING), leading to the recruitment of TBK1 and activation of the IRF3interferon axis (Chen and others 2016). Both cGAS and STING are expressed in human microglia and astrocytes (Jeffries and Marriott 2017), and in vivo studies have begun to establish the importance of cGAS-STING pathway both in CNS infection and in sterile inflammation. For example, cGAS or STING deficient mice are highly susceptible to herpes simplex encephalitis (HSE), abolishing microglial type 1 interferons and the ability of astrocytes to upregulate TLR3 (Reinert and others 2016). Self-DNA has been linked to inflammatory and autoimmune diseases such as systemic lupus erythematosus (SLE) and Aicardi-Goutieres syndrome (AGS), a congenital encephalopathy caused by mutations in nucleic acid degrading enzymes including TREX1 (Dhanwani and others 2018). Neurological impairment is accompanied by elevated levels of type 1 interferons in the CSF of AGS patients, and cGAS has recently been identified as the principal PRR responsible for mediating inflammation in TREX1 deficient mice, thus providing a key link between AGS, cGAS, and abnormal nucleic acid sensing in the CNS (Gao and others 2015; Gray and others 2015). Upregulation of cGAS also occurs in chronic neurodegeneration (Cox and others 2015); hence, increases in cell-free DNA coupled with increases in the expression of nucleic acid sensors during sterile inflammatory responses (or failure to regulate their expression during infection) has the potential to exacerbate already existing inflammation.
Another important cytosolic sensor, absent in melanoma 2 (AIM-2), can also directly bind dsDNA and is expressed by astrocytes and microglia (Cox and others 2015) to form an inflammasome complex with the adaptor protein, ASC, and the enzyme, caspase-1, leading to IL-1 $\beta$ processing and secretion (Place and Kanneganti 2018). IL-1 $\beta$ production and inflammasome activation is a two-step process in most cell types; a priming signal is required to upregulate the expression of pro-IL-1 $\beta$ and inflammasome components while a second signal leads to inflammasome assembly and caspase- 1 activation and is mediated by the inflammasome activator itself. The priming signal is provided in many cases by TLR-induced NF- $\kappa \mathrm{B}$ activation; however, as mentioned above, the presence of functional TLR responses in astrocytes is debated. Indeed, murine astrocyte cultures devoid of microglia and primed with TLR2, TLR3, and TLR4 ligands failed to secrete IL- $1 \beta$ in response to the inflammasome activator, ATP (Facci and others 2014), and we have also found this to be the case when using dsDNA to drive AIM2 mediated inflammasome activation in purified astrocytes (unpublished data). Furthermore, Barbierato and others (2013) demonstrated that rat astrocyte cultures failed to drive inflammasome dependent IL-1 $\beta$ production in isolation; however, when co-cultured with microglia, IL-1 $\beta$ production far exceeded that observed from cultures containing the same numbers of microglia alone, suggesting that microglia confer LPS responsiveness on astrocytes or, indeed, that astrocytes are enhancing inflammasome-dependent IL- $1 \beta$ production by microglia. The sensors and pathways involved in nucleic acid sensing are summarized in Figure 2.

\section{Phagocytosis, Immune Cell Infiltration, and Blood Brain Barrier in CNS Injury}

Although microglia are the professional phagocytes of the CNS, there is evidence that astrocytes have the molecular machinery to participate in phagocytosis (Cahoy and others 2008). Extracellular protein deposits such as Amyloid- $\beta$ constitute endogenous activators of astrocyte phagocytosis and overlay of $\mathrm{A} \beta$ plaque-containing cultures with astrocytes resulted in significant reduction of tissue A $31-42$ levels (Wyss-Coray and others 2003). Other in vitro studies have demonstrated CD47-, CD36-, and RAGE-mediated $\mathrm{A} \beta$ engulfment (Jones and others 2013). That this clearance function is biologically significant and that different aspects of astrocyte function may influence disease course in different ways is supported by findings that 1) ablating the intermediate filaments GFAP and Vimentin significantly reduced hypertrophy but also impaired amyloid clearance (Kraft and others 2013) but 2) suppressing astrocyte calcineurin/NFAT signaling improves amyloid pathology and cognitive function 


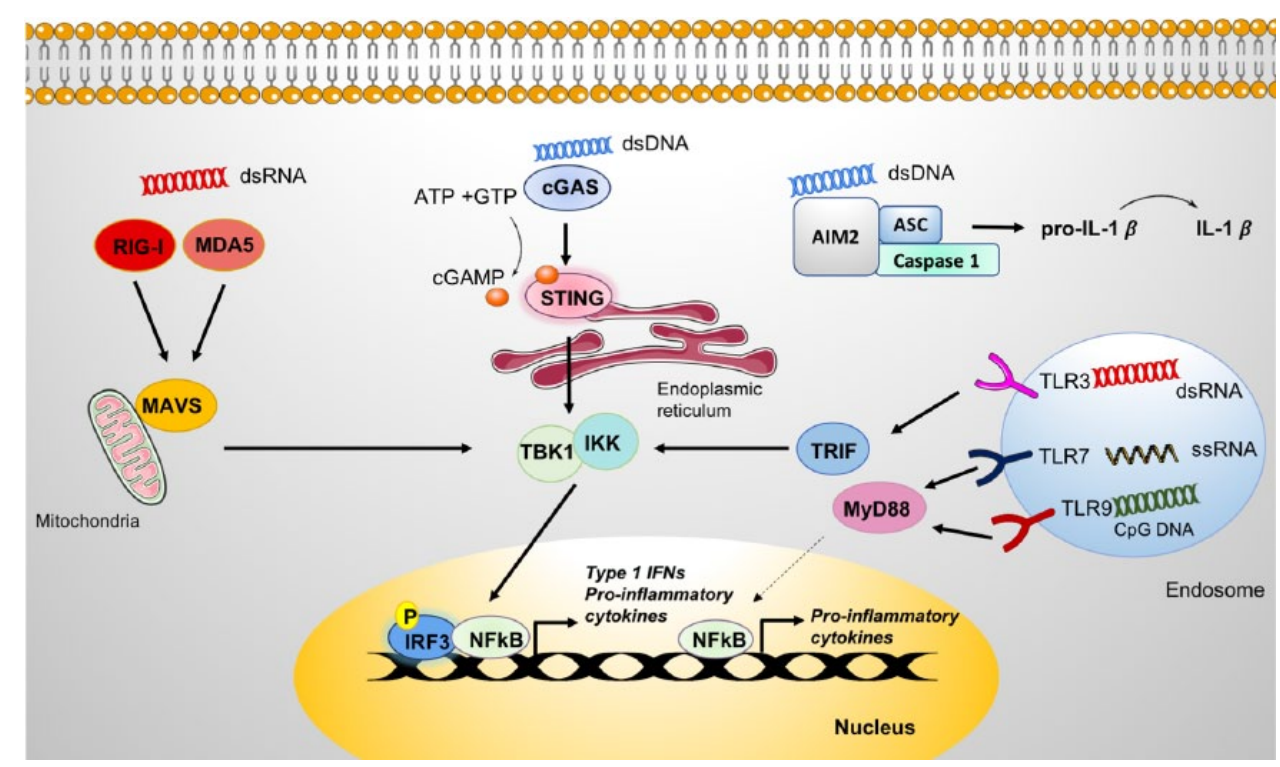

Figure 2. Nucleic acid sensing pathways in astrocytes. TLRs present in endosomal compartments utilize the adaptor proteins myeloid differentiation primary response gene 88 (MYD88) or TIR-domain-containing adaptor-inducing interferon (TRIF) to recruit downstream signaling molecules, which eventually culminates in the production of pro-inflammatory cytokines and/or type I interferons (IFN). Rig-I-Like Receptor (RLR) proteins, retinoic acid-inducible gene I (RIG), and melanoma differentiationassociated gene 5 (MDA5) signal through the mitochondrial adaptor protein MAVS (also called IPS-I, Cardif, and VISA) to trigger the production of type I interferons together with NF-кB. Upon binding cytosolic dsDNA, AIM2 forms an inflammasome with procaspase I and ASC to induce IL-I $\beta$ processing and secretion. The event likely required co-cooperativity between astrocytes and microglia.

(Furman and others 2012). Indeed, astrocytes also appear to engulf a small minority of dystrophic neurites around amyloid plaques in both mouse and human (GomezArboledas and others 2018). Astrocytes have been shown to mediate synapse elimination during development and in adulthood through MERTK, a known receptor for "eat me" signals during phagocytosis and MEGF10, an orthologue of Drosophila Draper and C. elegans CED-1 (Chung and others 2013). There are conflicting data as to whether this process requires $\mathrm{C} 1 \mathrm{q}$ to mediate uptake of synaptic terminals (Iram and others 2016; Stevens and others 2007). MEGF10 has also been shown to cooperate with $\mathrm{ABCA} 1$ during astrocyte uptake of apoptotic cells in ischemia. Consistent with discrete and complementary roles, microglia were more phagocytically active in the ischemic core at early time points while astrocytes were more active in the penumbra at later times post-lesion (Morizawa and others 2017). Thus, in health and disease, astrocytes appear competent for phagocytosis, although their contribution, relative to microglia, remains incompletely characterized.

Increased myelin debris has also been shown inside reactive astrocytes in human MS lesions and this appears to be an early clearance event that contributes to astrocyte activation and immune cell infiltration via chemokine expression (Ponath and others 2017). Indeed, the regulation of the innate immune response to brain injury may be heavily influenced by initial astrocyte responses: axonal injury in the perforant path (from entorhinal cortex to hippocampal dentate gyrus) leads to significant astrocyte expression of chemokines CCL2 and CCL5 and the former contributes significantly to monocyte and T-cell infiltration (Babcock and others 2003). Axonal transection also rapidly induces type I interferon responses and STAT1/2 signaling in astrocytes and astrocyte-specific inhibition of NFKB suppressed CCL2 expression and leukocyte infiltration (Khorooshi and Owens 2010, Khorooshi and others, 2008). A wide range of chemokines are secreted by both murine and human astrocytes upon IL-1 stimulation (Choi and others 2014; John and others 2005) and this regulation of leukocyte infiltration represents a key astrocyte contribution to innate immunity.

Infiltration of inflammatory cells into the brain is restricted by the BBB. This barrier, consists of a specialized non-fenestrated endothelial cell layer expressing tight junctions and an astrocyte endfoot layer, separated from each other by a basement membrane layer that comprises distinct endothelial and astrocytic basement membranes (the latter more commonly known as the perivascular glia limitans). Perivascular astrocytes are 
essential for functional barrier capacity of the BBB and endfeet proteins including Aquaporin 4, Kir4.1, and $\mathrm{Cx} 43$ contribute to water and electrolyte movement and barrier function (Alvarez and others 2013). Sonic hedgehog $(\mathrm{SHH})$ is among several astrocyte proteins contributing to BBB integrity and astrocyte $\mathrm{Cx} 43$ also has a key role in maintaining immune quiescence in the CNS, preventing $B$ and $T$ cell infiltration and autoimmunity (Boulay and others 2015). Both SHH and $\mathrm{Cx} 43$ are downregulated by IL-1 $\beta$ effecting increased permeability in the BBB (Wang and others 2014; Watanabe and others 2016). Loss of astrocyte endfoot coverage of the glia limitans is a striking feature of active MS lesions, allowing leukocytes to transmigrate from the Virchow Robin space across the glia limitans and into the brain parenchyma (Brosnan and Raine 2013). Thus, normal astrocyte function is essential to BBB integrity and immune regulation in the brain and actions of proinflammatory cytokines can alter permeability to leukocytes via effects on the perivascular astrocyte.

\section{Antigen Presentation and T-Cell Interactions}

Although astrocytes seem well placed, at the blood brain interface, to present antigen and can be induced to express MHC class II and can present antigen to T-cells that have already been activated with brain-specific antigens (Fierz and others 1985), they seem to lack the necessary costimulatory molecules to act as efficient antigen presenting cells (Williams and others 1995). Nonetheless, in disease states such as multiple sclerosis, and its rodent model EAE, $T$ cells can infiltrate the brain and key $\mathrm{T}$ cell secretory products such as IFN $\gamma$ and IL-17 are known to have significant impacts on astrocyte function. Although IFN $\gamma$ has detrimental roles in EAE, astrocyte-specific deletion of IFN $\gamma \mathrm{R}$ causes increased CCL2, CCL5, and CXCL10 expression and leukocyte infiltration (Hindinger and others 2012) while targeting Act1, an NFкB activator on the IL-17R signaling pathway, in astrocytes is effective in treating EAE-induced inflammation (Yan and others 2012).

\section{Astrocyte Activation in Injury and Pathology}

After any CNS insult or during neurodegenerative disease, astrocytes become reactive and evidence suggests they lose many normal functions and gain new abnormal roles that can contribute to pathology (Verkhratsky and Nedergaard 2018). This "astrocytosis" may consist of proliferation, morphological changes, enhancement of GFAP expression, and changes in gene, molecular, and metabolic profile. Astrocytes may promote neuronal survival by the production and release of neurotrophic and growth factors and contribute to tissue consolidation and remodeling by the formation of glial scars. It is already abundantly clear that the ablation or removal of astrocytes is detrimental in models of stroke and spinal cord injury (Burda and Sofroniew 2014) emphasizing that the response of astrocytes to brain injury is an essential part of recovery. Therefore, questions about whether astrogliosis is beneficial or detrimental will be context- and timing-dependent and unravelling different aspects of astrocyte phenotype will be essential.

Just as for healthy astrocytes, and despite a long-standing binary nomenclature (reactive or not), astrogliosis is also a heterogeneous process, and its nature and extent depends on the context and severity of the insult and the time point with respect to the onset of the brain insult (Sofroniew and Vinters 2010). The multicellular response to acute injury comprises three phases: cell death and initiation of inflammation (within hours), tissue replacement (days to weeks), and tissue remodeling (longer periods). Inflammatory changes occur rapidly: microglia are the most rapid and motile responders after acute injury (Nimmerjahn and others 2005) while astrocytes do not migrate to the injury site but may swell, hypertrophy, and proliferate (Burda and Sofroniew 2014). During tissue replacement some BBB breakdown may persist, thereby allowing serum proteins like thrombin and albumin access to the brain tissue, and the formation of a compact glial scar becomes an important protective mechanism for separating the lesion core, with its serum proteins and inflammatory infiltrates, from the surrounding tissue during repair of the vasculature. In this sense glial scarring is clearly beneficial in acute injury models ( $\mathrm{Li}$ and others 2008; Wanner and others 2013). Astrocytes also contribute to BBB repair in this phase (Wanner and others 2013). Therefore, temporal aspects of the response to acute injury are major determinants of the phenotype of astrocytes.

Astrocytes also show heterogeneity in molecular phenotype as a function of the severity of the reactive astrocytosis present in injured or diseased tissue. Sofroniew and colleagues have described astrogliosis as a finely graded continuum of progressive changes in gene expression and cellular changes but nonetheless offer a classification (Sofroniew and Vinters 2010) that recognizes three broad categories (with normal/healthy tissue astrocytes making a fourth):

1. Normal: Not all astrocytes express GFAP, their domains are non-overlapping, and they show little or no proliferation.

2. Mild to moderate astrogliosis: Most astrocytes are GFAP + but there remains no significant overlapping or proliferation (associated with non-penetrating/non-contusive trauma and with diffuse innate immune activation/systemic inflammation) 
3. Severe diffuse reactive astrocytosis: Most astrocytes are GFAP + but with disruption of individual domains and with significant proliferation (associated areas around severe focal lesions and regions affected by chronic neurodegeneration)

4. Severe astrogliosis with compact glia scar formation: Bordering tissue damage and forming a barrier that is not permissive to axons, infectious agents, or non-CNS cells (associated with penetrating/contusive trauma, invasive infections/neoplasms and chronic neurodegeneration)

Although there is now a wealth of molecular characterizations of astrocyte phenotypes in different pathological situations, these studies have not explicitly aimed at molecular definition of the four states mentioned above. Rather authors have investigated astrocyte changes in specific pathology settings and it is informative to examine some of these. Transcriptomic studies (Cahoy and others 2008; Lovatt and others 2007) provide a lot of information on "normal" astrocytes and these have already been discussed. At the severe end of the scale, transcriptomic studies of glial scarring in spinal cord injury reveal that both time since injury and severity of injury are major determinants of the phenotype. While Gfap and Serpina3n remained elevated with both severities and throughout 2 weeks, inflammation predominated at 1 week post-full transection (complement factors, interferon stimulated genes, antigen presentation, Stats) but was relatively muted in hemisection astrocytes. The major change at 2 weeks post-full transection was the downregulation of tissue degradation and proteolysis pathways (Noristani and others 2016).

Despite the four broad classifications of Sofroniew, there are clearly areas of overlap between "moderate" and "severe," and in particular, chronic neurodegenerative disease is associated with severe astrogliosis with or without glial scar formation.

\section{Molecular Characterizations of Astrocyte Phenotypes}

\section{Systemic Inflammation}

GFAP expression is a key measure of "mild to moderate" astrogliosis, and studies of systemic inflammation confirmed increased Gfap transcription as early as 6 hours post LPS or poly I:C (Biesmans and others 2015). Although LPS (0.3-0.6 mg/kg) left GFAP immunolabeling relatively unchanged by 12 hours, it induced $C c l 2$, IllO, and Tgfbl in astrocytes, while $I l 1 b$ and $I l 6$ were preferentially expressed by microglia (Norden and others 2016). At higher doses of LPS (3 mg/ $\mathrm{kg}$ ), GFAP, vimentin, and several chemokines were elevated in astrocytes (Hasegawa-Ishii and others 2016) and similar results were shown 24 hours post-LPS $(5 \mathrm{mg} /$ $\mathrm{kg}$ ). A detailed transcriptomic analysis of astrocytes from that study (Zamanian and others 2012) is presented below. Although peripheral LPS is described as a model of neuroinflammation, it is important to note that at higher doses $(>1 \mathrm{mg} / \mathrm{kg})$ this is a model of moderate to severe sepsis, causing robust systemic inflammation and some neurodegeneration in the brain (Semmler and others 2005) and this may place the resulting astrocytosis on the moderate or severe rather than mild end of the scale.

\section{Sepsis versus Stroke}

Experimenters have begun to characterize the molecular distinctions between astrocytes activated by different acute stimuli involving acute neurodegeneration. In one useful study, astrocytes isolated from the brains of mice treated with $5 \mathrm{mg} / \mathrm{kg}$ LPS or from animals subjected to the middle cerebral artery occlusion model of stroke were analyzed at the transcriptomic level and showed temporally defined patterns of astrocytic gene expression (Zamanian and others 2012). The analysis of astrocytosis at 1 day post-MCAO and 1 day post-LPS showed substantial differences between these astrocyte populations. Although transcripts for Lcn2, Steap4, Gfap, Cxcl10, Timp1, S1pr3, Serpina3n, and others were highly expressed in both insults, there was significant divergence between their profiles. MCAO drove a profile characterized by increased metabolic activity, cell-cycle genes, and transcription factors, while LPS drove a more immune-mediated, NFкB-driven response with prominent complement, antigen presentation, and interferonresponse pathways (Zamanian and others 2012).

Although the authors concluded that reactive astrogliosis was likely a highly heterogeneous state and speculated on how many subtypes of astrocytes exist, surprisingly this study also provided the platform for the view that reactive astrocytes may take up one of 2 polarized states, now termed A1 and A2 (Liddelow and others 2017). Following the studies of Zamanian and others (2012), these authors showed that the astrocyte profile produced by high-dose systemic LPS (in vivo) did not occur in animals lacking microglia due to deletion of Csf1r. Therefore, microglia activation licenses this pro-inflammatory astrocyte phenotype. Interrogating inflammatory mediators responsible for this, they identified IL- $1 \alpha$ as strongly inducing the "A1" phenotype, while IL-1 $\beta$ induced a number of "A2" transcripts and a smaller number of "A1" transcripts. While both TNF- $\alpha$ and C1q were relatively weaker inducers of A1 transcripts, when combined with IL-1 $\alpha$ they produced a very polarized "A1" phenotype. The ability of microglial LPS-conditioned media to induce this A1 phenotype in 
cultured astrocytes was completely ablated using neutralizing antibodies against IL- $1 \alpha$, TNF- $\alpha$, and C1q and astrocytes from mice with deletions of Illa, Tnf, and Clq also failed to adopt this polarized state. The growth factors FGF and TGF $\beta 1$ were also able to reverse the A1 phenotype 24 hours after its induction. These polarized A1 astrocytes failed to support synaptic function, were inefficient at phagocytosis of myelin, and cultured media from these astrocytes were neurotoxic to retinal ganglion cells, spinal motor neurons, and cortical neurons (Liddelow and others 2017). Such an astrocyte phenotype, in vivo, would appear to be extremely deleterious.

This study also contains a very large data set examining the influences of many inflammatory and growth factors on astrocyte phenotype and will be a valuable source of information and testable hypotheses. However, some caution is required. The microglial milieu inducing this A1 phenotype may constitute a sort of "perfect storm" of inflammatory mediators that occurs only in severe situations. In proposing these polarized states, there is a significant risk that the complexity of the factors shaping astrocyte phenotype may be oversimplified and that rather small panels of genes may be adopted by researchers to infer whether astrocytes adopt these polarized A1/ A2 phenotypes, which could be misleading in the way that the, now abandoned, M1/M2 nomenclature has been for the microglial field. The question of whether chronic CNS pathologies conform to this A1/A2 dichotomy needs to be addressed.

\section{Aging}

Boisvert and others (2018) analyzed the aging astrocyte transcriptome from different brain regions of mice revealing significant elevation of a number of pan-reactive, A1 and $A 2$ transcripts with relatively similar fold increases in A1 and A2 categories. Among the "A2" genes elevated were Tgm1, S100a10, Ptx3, and Emp1. In another aging study, astrocytes from the hippocampus and striatum of 2-year-old mice were described as showing an "A1-like" phenotype and this phenotype failed to emerge in Illa/ Tnf/Clq triple knockout mice (Clarke and others 2018). However, adoption of a microfluidic device containing only the pre-selected genes assembled from the original A1/A2 studies effectively constrained the study to conform to the A1/A2 terminology but the profile described as "A1-like" comprised several genes from both designations "A1-specific" and "A2-specific" (Tgm1, s100a10, Slc10a6, Cd14) and the distribution of A1 and A2 specific genes is relatively even among wild type animals in those experiments where they are compared to the triple knockout. Therefore, the knockout of Illa/Tnf/Clq significantly mitigates overall astrocyte reactivity but a phenotype comprising relatively equal numbers of "A1-specific" and "A2-specific" transcripts cannot be described as conforming to the polarized A1 state. Valuable as the data are to understand astrocytic changes with age, it is important that ill-fitting categorical phenotypic designations are not imposed on emerging data. A more flexible classification of astrocytes would be more appropriate.

Indeed, that different stimuli might differentially shape astrocyte phenotype is intuitive and the possibilities are almost endless. One study (Hamby and others 2012) used astrocytes (cultured from p1-3 neonatal mice, treated with cytosine- $\beta$-D-arabinofuranoside and L-leucine methylester to remove microglial impurities) to examine the divergent astrocyte profiles induced by TGF $\beta 1$, LPS + IFN $\gamma$, or all three in combination compared to the basal condition. TGF $\beta 1$ produced a strikingly different profile from those cultures treated with LPS, with LPS predictably driving immune-signaling pathways but TGF $\beta 1$ driving cell development, growth and proliferation, and lipid metabolism pathways. Adding TGF $\beta 1$ to cultures simultaneously with LPS + IFN $\gamma$ produced 1038 differences from LPS+IFN $\gamma$ alone, and although many LPS-induced effects remained, there were a significant number of genes for which the treatments produced synergistic effects that would not have been predicted from summation of effects alone. For example, while LPS induced Il6, Nos2, and Lif and TGF $\beta 1$ did not, TGF $\beta 1$ amplified the induction of these inflammatory transcripts by LPS. What these multiple changes in transcriptional profile mean for function cannot easily be determined, but a predominance of decreased expression of transcripts and signaling effectors for $\mathrm{G}$ protein-coupled receptors lead to a demonstration of downregulation of intracellular $\mathrm{Ca}^{2+}$ increases in astrocytes treated with agonists for chemokine, adrenaline, and purinergic receptors (Hamby and others 2012). Thus, combinatorial treatments can produce multiple different functional states in astrocytes and it is hard to imagine that activated astrocytes could adopt one of only two polarized states. Although an enormous number of potential activating factors were tested and failed to produce the polarized states induced by IL-1 $\alpha+\mathrm{TNF}-\alpha+\mathrm{C} 1 \mathrm{q}$ (Liddelow and others 2017), several molecules including CCL2, S1P, and IGF1 stimulated profiles that were a modest, but relatively equal, assortment of pan-reactive and putative A1 and A2 transcripts, while IL-10 stimulated several of all three categories and TGF $\beta 1$ induced several $\mathrm{A} 1$ and $\mathrm{A} 2$ transcripts despite affecting very few supposedly panreactive genes. Those data emphasize the multitudinous phenotypic possibilities with different activation factors, and if different combinations of such activators were applied, the scope for a broad spectrum of phenotypes is manifest. 


\section{Chronic Neurodegeneration}

Chronic neuroinflammation does not produce astrocyte phenotypes conforming to those induced by LPS or MCAO. Transcriptomic studies of astrocytes isolated from brains of APP/PS1 mice, showing robust amyloid pathology relevant to AD (Orre and others 2014), demonstrated that astrocytes from 15- to 18-month-old APP/PS1 cortices show a marked increase in expression of genes underpinning pro-inflammatory responses. Indeed, many of the genes elevated in the astrocyte preparations were markers more traditionally associated with microglia (such as Clec7a, Tyrobp, Trem2, Itgax, Cd14, IL-1, Cst7, Csf1r, Cx3cr1, Lgals1, Aif1). Directly comparing expression patterns to those of LPS and MCAO at 24 hours (Zamanian and others 2012), the authors revealed that there was a large cluster of differentially regulated genes that showed no overlap with either LPS or MCAO, illustrating that $\mathrm{A} 1$ and $\mathrm{A} 2$ phenotypes do not capture the profile of astrocytes in this model. Indeed, the top 100 upregulated genes in the Orre APP/PS1 study contained just one A1 gene, one A2 gene, and two "pan-reactive genes" identified in the top 50 upregulated genes from the LPS/MCAO study (Zamanian and others 2012). Several "pan-reactive genes" (Liddelow and others 2017) were not elevated in this AD model, suggesting that those are not actually "pan-reactive" genes with respect to chronic neuroinflammation. The cluster of genes that did overlap with LPS and MCAO profiles showed relatively similar upregulation of $\mathrm{A} 1$ and $\mathrm{A} 2$ genes and the strongest overlap between all these models was in downregulated genes. These included genes involved in glutamate transport and metabolism, Notch signaling, $\mathrm{K}^{+}$channels, and ion/fluid balance. This is concordant with recent data (Hasel and others 2017): astrocytes living in close proximity with neurons express Hes 5 and Hey2, and when those neurons are absent, are removed, or enter a degenerative state, astrocytes downregulate a large panel of genes involved in neuronal support.

In the P301S model of tau pathology, despite clear GFAP-positive astrocytosis, there was little evidence of expression of pan-reactive, A1 or A2 transcripts. However, when the Tau transgene was expressed on an ApoE4 background, the expression of A1 genes was moderately increased, although this represented only subsets of pan-reactive and A1 genes and only in some animals (Shi and others 2017). In two models of Parkinson's disease, glucagon-like peptide 1 receptor agonists prevented neurotoxicity and spread of $\alpha$-synuclein pathology and this was described as mediated by the prevention of adoption of the A1 astrocyte phenotype (Yun and others 2018). However, the preselected astrocyte transcript 'target' panels limit the phenotypic characterization of astrocytes provided in these models.
Overall the data from chronic neurodegeneration indicate that the binary classification of reactive astrocytes is untenable and perhaps the recently described A1 phenotype most clearly demonstrates that a polarized state is possible when subjected to multiple different pro-inflammatory mediators, released from microglia at their own "most pro-inflammatory" state. There may be a finite number of somewhat polarized phenotypes after robust and acute stimulation (LPS at $5 \mathrm{mg} / \mathrm{kg}$ and MCAO both meet that criterion) but those chronic disease models in which astrocytes have been isolated and analyzed show profiles that diverge from the $\mathrm{A} 1$ and indeed pan-reactive profiles. This is analogous to the marked differences between microglia in neurodegenerative disease and the classical pro-inflammatory, NFкB-driven, "M1-like" microglia arising after LPS stimulation (Holtman and others 2015). However, all insults that produce neurodegenerative consequences may share some overlap in a program of gene regulation that suppresses astrocyte support of neuronal function.

\section{Sequential Activation, Astrocyte Priming, and Phenotype Switching}

Our own work provides further evidence that astrocytes adopt further phenotypic states. Although astrocytes in animal models of both prion disease (ME7) and Alzheimer's disease (APP/PS1) show astrogliosis, that is, morphologically, in the severe range, they express relatively low levels of many of the chemokines associated with robust astrocyte activation in transcriptomic studies. However, upon secondary inflammatory challenge with the cytokines IL- $1 \beta$ or TNF- $\alpha$, these astrocytes switch phenotype and make very significant levels of chemokines such as CCL2, CXCL1, and CXCL10 demonstrable specifically in diseased-associated astrocytes only upon secondary challenge (Hennessy and others 2015; Lopez-Rodriguez and others 2018). One striking feature in these disease models was that despite the clear astrocytosis present in disease, nuclear localization of $\mathrm{NF \kappa B}$ p 65 was absent in disease per se and only becomes localized to the nucleus after secondary inflammatory challenge. The reported A1 phenotype is heavily dependent on $\mathrm{NF \kappa B}$ activation (Liddelow and Barres 2017) but astrocytic NFKB activation appears more limited in models of chronic neurodegeneration (Ben Haim and others 2015; Crosio and others 2011; Lopez-Rodriguez and others 2018).

Some earlier data had suggested hypersensitive astrocyte responses emerging in combinatorial or sequential treatment designs in vitro: co-treatment of astrocytes with IFN $\gamma$ facilitated significantly more robust responses to IL-1 (Chung and Benveniste 1990), while prior exposure to IL-1 $\beta$, to TLR3 ligands, or to an IL- $1+\mathrm{TNF} \alpha+\mathrm{IFN} \gamma$ 


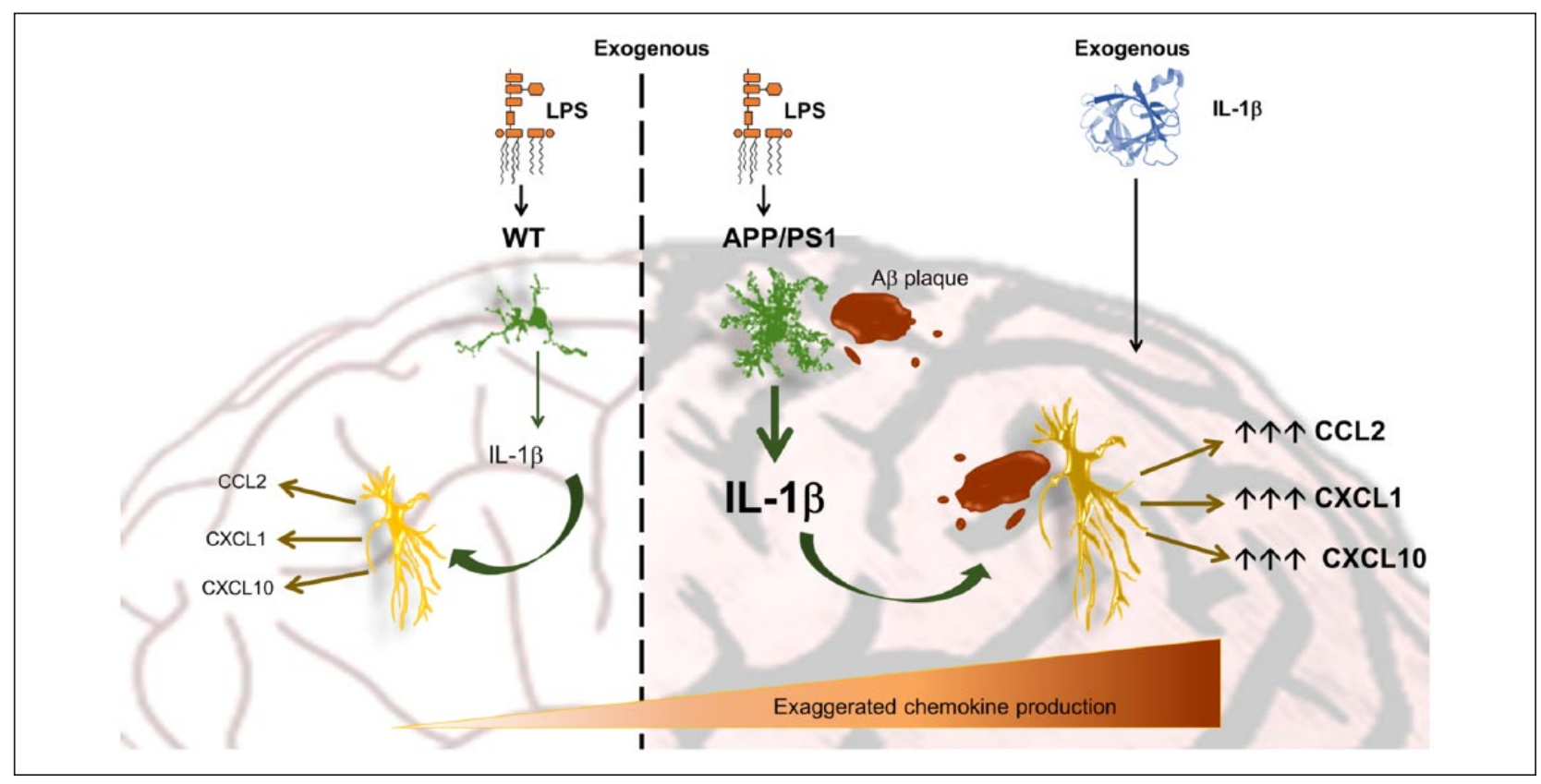

Figure 3. Microglial and astrocyte priming facilitate an inflammatory amplification loop. During exposure to pro-inflammatory stimuli such as bacterial endotoxin (LPS) microglia in normal mice (left) synthesize IL- I $\beta$ and this IL- I $\beta$ may activate astrocytes to release chemokines such as CCL2, CXCLI, or CXCLI0. During neurodegenerative disease microglia become activated or "primed" to show exaggerated IL-I $\beta$ responses to LPS and these enhanced IL-I $\beta$ levels may produce further chemokine synthesis. However, astrocytes also display a "primed" phenotype in animal models of neurodegenerative disease (ME7, APP/ PSI) and upon sensing a secondary inflammatory stimulus, primed astrocytes also respond in a hypersensitive way, secreting exaggerated levels of chemokines. Therefore, if levels of IL-I $\beta$, released by primed microglia, are already exaggerated this will produce a further amplification upon stimulating IL-I-hypersensitive astrocytes. This inflammatory amplification loop, comprising exaggerated IL-I production in addition to IL-I-hypersenstive astrocytes, leads to dramatic chemokine production and excessive inflammatory cell infiltrates (Hennessy and others 20I5).

cocktail left astrocytes hypersensitive to subsequent stimulation with TLR2 agonists (Henn and others 2011). In those experiments NFKB nuclear localization and chemokine synthesis were the outcomes that revealed the exaggerated astrocyte responses. Astrocytes "primed" with TNF $\alpha$ or those prepared from hSOD1G93A mice showed elevated expression of $\alpha_{\mathrm{v}} \beta_{3}$ integrin, $\mathrm{P} 2 \times 7 \mathrm{r}$, pannexin, and connexin- 43 , which would increase their reactivity to various subsequent stimuli and, in that study, increased Thy-1-induced cell migration (Lagos-Cabré and others 2017).

Therefore, "priming" of astrocytes by primary pathology to show exaggerated responses to subsequent stimuli is likely to be a general feature of astrocytes and should replicate in further models, with perhaps some differences predicted depending on the primary pathology. The primed astrocytes of the ME7 brain (i.e., those that robustly expressed chemokines upon secondary challenge) were prominent in the stratum radiatum of the hippocampal CA1, which, at that time, undergoes massive presynaptic terminal loss (Cunningham and others 2003) while those in the APP/PS1 brain were predominant in the dentate gyrus directly adjacent to $\mathrm{A} \beta$ plaques and did not occur distal from these plaques (Lopez-Rodriguez and others 2018). Therefore, the proximity of astrocytes to specific pathological features has a major impact on the phenotype they adopt, and their susceptibility to further activation upon secondary challenge. Other studies in ageing also suggest that astrocyte-derived chemokines like CXCL10 show exaggerated synthesis when aged animals are exposed to systemic LPS challenge (Clarke and others 2018), providing further evidence for priming of astrocytes and switching of phenotype upon secondary challenge. Therefore, however the phenotype of astrocytes in these diseases and ageing models might be defined, they clearly can change their phenotype once again upon a subsequent change to their environment: phenotype is plastic and exists on some continuum of different states depending on the local molecular milieu. In the context of chronic neurodegeneration, in which microglia are already primed to produce exaggerated IL-1 $\beta$ responses to subsequent inflammatory stimuli (Cunningham and others 2005; Holtman and others 2015), astrocytes are also hypersensitive to IL-1 stimulation and this may facilitate an amplification loop (Fig. 3) that seems likely to produce a deleterious, $\mathrm{NF \kappa B}$-driven and highly inflammatory astrocyte phenotype (Hennessy and others 2015; Lopez-Rodriguez and others 2018). 


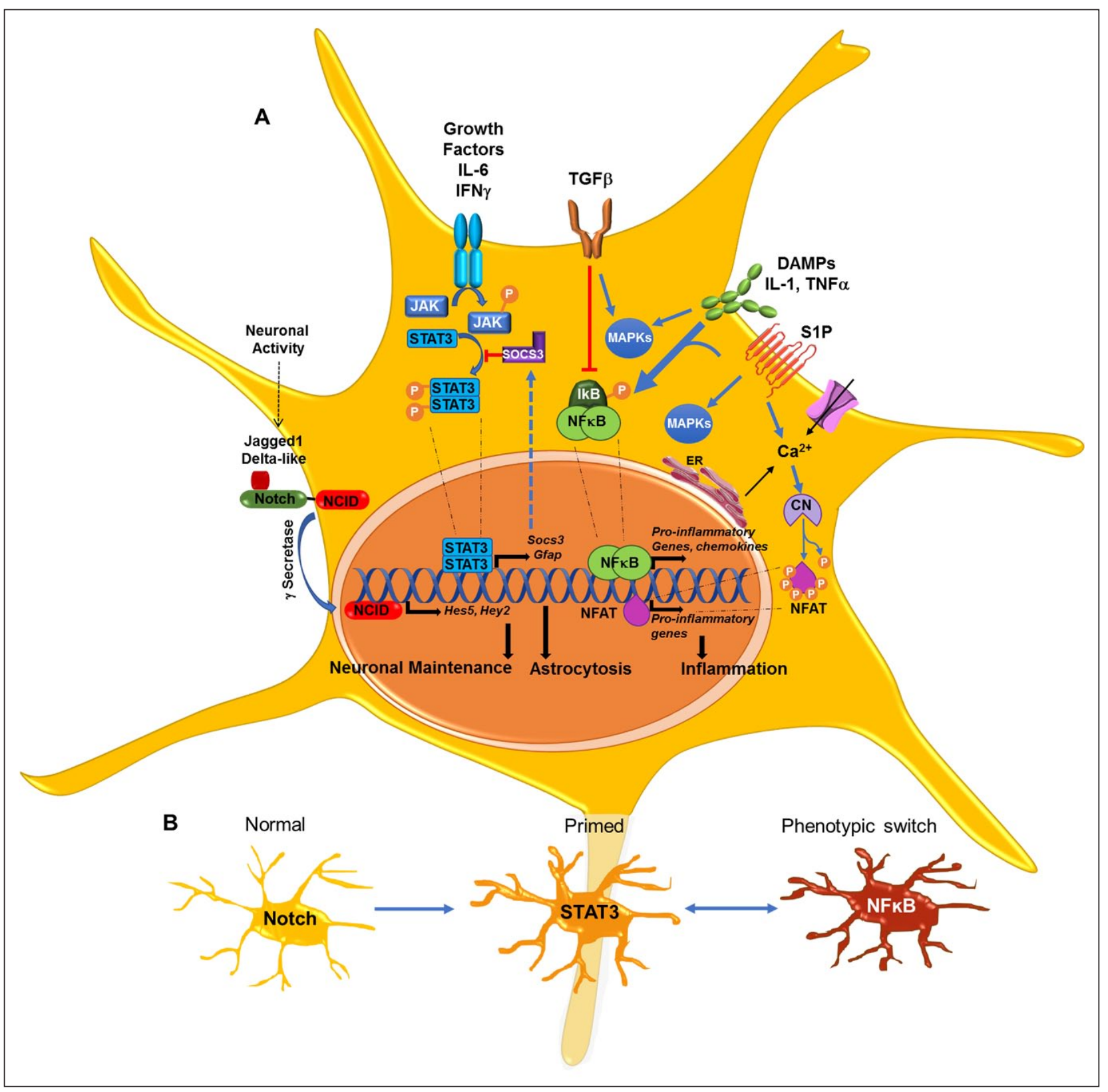

Figure 4. Astrocyte signaling pathways activated during CNS pathology. (A) Crosstalk of different signaling pathways in astrocytes that regulate neuronal maintenance, astrocytosis, and inflammatory processes. A small selection of transcriptional consequences is indicated. Blue arrow: activation. Red line: inhibition. Neuronal activity promotes constitutive Notch signaling via NCID regulation of many transcripts supporting neuronal metabolism and synaptic function. Loss of this signaling contributes to astrocyte activation. STAT3 activation drives Socs3 transcription, which contributes to feedback inhibition of STAT3 activation. TGF $\beta$ I, in addition to providing suppression of NFKB, is also an activator of SMAD proteins (not shown) and of mitogen activated protein kinases (MAPKs). The latter have been shown without reference to specific examples or transcriptional consequences due to the enormous variety of these proteins and the complexity of their signaling consequences. SIP signaling interacts with multiple signaling pathways, promoting NFkB, activating MAPKs, and elevating cellular $\mathrm{Ca}^{2+}$. NICD = notch intracellular domain; IL- = interleukin-; IFN $\gamma=$ interferon $\gamma ;$ JAK = Janus kinase; STAT3 = signal transducer and activator of transcription 3; SOCS3 = suppressor of cytokine signaling 3; TGF $\beta=$ transforming growth factor $\beta$; IkB = inhibitor of nuclear factor kappa-B; NFkB = nuclear factor kappa-B; DAMPS = damage-associated molecular pattern; TNF $\alpha=$ tumor necrosis factor $\alpha$; SIP = sphingosine-I-phosphate; ER = endoplasmic reticulum; $C N=$ calcineurin; NFAT = nuclear factor of activated T-cells. (B) Proposed scheme for key stages in the sequential development of phenotypic changes in astrocytes during pathology: loss of Notch signaling may combine with STAT3 activation to produce astrocytosis although NFKB activation may not occur in all pathological situations but does arise upon secondary inflammatory insults. 
Table I. Selection of Signaling Pathways Selectively Manipulated in Astrocytes, with Pathological Consequences.

\begin{tabular}{|c|c|c|c|c|c|c|}
\hline Target & Model & Manipulation & $\Delta$ & Biological Effect & Disease Outcome & References \\
\hline \multirow[t]{3}{*}{ STAT3 } & $\mathrm{SCl}$ & $\begin{array}{l}\text { GFAP-Cre- } \\
\text { STAT3 }\end{array}$ & - & $\begin{array}{l}\downarrow \text { Regrowth of axons } \\
\downarrow \text { GFAP }+ \text { astrocytes } \\
\downarrow \text { Astrocytes proliferation } \\
\downarrow \text { Scar formation } \\
\uparrow \text { Non-neural tissue around } \\
\text { lesion area }\end{array}$ & $\begin{array}{l}\downarrow \text { Recovery ( } 28 \text { days) } \\
\uparrow \text { Demyelination } \\
\uparrow \text { Neuronal loss } \\
\uparrow \text { Spread of inflammation } \\
\uparrow \text { Lesion volume }\end{array}$ & $\begin{array}{l}\text { (Anderson and others } \\
\text { 20I6; Herrmann and } \\
\text { others 2008; Wanner } \\
\text { and others 20I3) }\end{array}$ \\
\hline & & $\begin{array}{l}\text { Nes-Cre- } \\
\text { STAT3 } 3^{\text {loxP/loxP }}\end{array}$ & - & $\uparrow \mathrm{CdIIb}+$ & $\uparrow$ Demyelination & $\begin{array}{l}\text { (Okada and others } \\
\text { 2006) }\end{array}$ \\
\hline & WMI & $\begin{array}{l}\text { GFAP-Cre- } \\
\text { STAT3 } \\
\text { loxP/loxP }\end{array}$ & - & $\begin{array}{l}\downarrow \text { Oligodendrocyte } \\
\text { maturation } \\
\uparrow \mathrm{TGF} \beta-I\end{array}$ & $\uparrow$ White matter injury & $\begin{array}{l}\text { (Nobuta and others } \\
2012 \text { ) }\end{array}$ \\
\hline \multirow[t]{2}{*}{ SOCS3 } & $\mathrm{SCl}$ & $\begin{array}{l}\text { Nes-Cre- } \\
\text { SOCS3 }\end{array}$ & - & $\uparrow$ Astrocyte migration & $\begin{array}{l}\downarrow \text { Lesion volume } \\
\uparrow \text { Functional recovery }\end{array}$ & $\begin{array}{l}\text { (Okada and others } \\
\text { 2006) }\end{array}$ \\
\hline & $\begin{array}{l}3 \times T g A D \\
H t t 82 Q\end{array}$ & $\begin{array}{l}\text { Lenti-SOCS3 } \\
\text { Lenti-GFP }\end{array}$ & + & $\begin{array}{l}\downarrow \text { Pro-inflammatory cytokines } \\
\downarrow \text { Astrocyte and microglia } \\
\text { reactivity }\end{array}$ & $\uparrow$ Huntingtin aggregates & $\begin{array}{l}\text { (Ben Haim and others } \\
\text { 20I5) }\end{array}$ \\
\hline \multirow[t]{3}{*}{$N F-\kappa B$} & $\mathrm{SCl}$ & 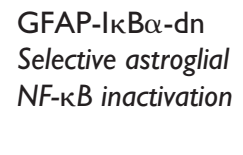 & - & $\begin{array}{l}\downarrow \mathrm{CXCL}-10, \mathrm{CCL} 2, \mathrm{TGF} \beta \\
\uparrow \text { Synaptic and axonal growth } \\
\text { molecules }\end{array}$ & $\begin{array}{l}\downarrow \text { Lesion volume } \\
\uparrow \text { White matter } \\
\text { preservation } \\
\uparrow \text { Functional improvement }\end{array}$ & $\begin{array}{l}\text { (Brambilla and others } \\
\text { 2005; Brambilla and } \\
\text { others 2009b) }\end{array}$ \\
\hline & $\mathrm{EAE}$ & & & $\begin{array}{l}\downarrow \text { Pro-inflammatory genes } \\
\downarrow \text { Peripheral infiltration } \\
\downarrow \text { Microglia activation } \\
\uparrow \text { Leukocytes } \\
\uparrow \text { CD8+CDI } 22+\text { T cells }\end{array}$ & $\begin{array}{l}\downarrow \text { Demyelination } \\
\downarrow \text { Cell death } \\
\uparrow \text { Remyelination }\end{array}$ & $\begin{array}{l}\text { (Brambilla and others } \\
\text { 2012; Brambilla } \\
\text { and others 20I4; } \\
\text { Brambilla and others } \\
\text { 2009a) }\end{array}$ \\
\hline & Cprz. & & & $\begin{array}{l}\downarrow \text { Pro-inflammatory cytokines } \\
\downarrow \text { Glial response }\end{array}$ & $\uparrow$ Myelin preservation & $\begin{array}{l}\text { (Raasch and others } \\
2011 \text { ) }\end{array}$ \\
\hline NFAT & $5 x F A D$ & $\begin{array}{l}\text { AAV-VIVIT } \\
\text { Selective astroglial } \\
\text { NFAT inactivation }\end{array}$ & - & $\begin{array}{l}\downarrow \text { Glutamate hyperexcitability } \\
\downarrow \text { Dendritic degeneration } \\
\uparrow \text { Synaptic strength } \\
\uparrow \text { GLT-I expression } \\
\downarrow \text { NMDAR responses }\end{array}$ & $\begin{array}{l}\downarrow A \beta \text { plaque load } \\
\uparrow \text { Cognition }\end{array}$ & $\begin{array}{l}\text { (Sompol and others } \\
2017 \text { ) }\end{array}$ \\
\hline $\mathrm{CN}$ & $\begin{array}{l}\text { Stab } \\
\text { Wound }\end{array}$ & $\begin{array}{l}\text { PGFAP- } \Delta \mathrm{CnA} \\
\text { Overexpression of } \\
\text { calcineurin } \\
\text { in astrocytes }\end{array}$ & + & $\begin{array}{l}\uparrow \text { SOD and IGF-I } \\
\downarrow \text { GFAP, COX-2, CdI Ib } \\
\downarrow \text { NFKB pathways }\end{array}$ & $\begin{array}{l}\uparrow \text { Injury resolution } \\
\downarrow \text { Neuronal death }\end{array}$ & $\begin{array}{l}\text { (Fernandez and others } \\
\text { 2007) }\end{array}$ \\
\hline \multirow[t]{2}{*}{ gp/30 } & TE & $\begin{array}{l}\text { GFAP-Cre- } \\
\text { gp } 130^{\text {loxP/loxp }}\end{array}$ & - & $\downarrow$ GFAP + astrocytes & $\begin{array}{l}\downarrow \text { Parasite control } \\
\uparrow \text { Lesion volume } \\
\uparrow \text { Necrosis }\end{array}$ & $\begin{array}{l}\text { (Drögemüller and } \\
\text { others 2008) }\end{array}$ \\
\hline & $\mathrm{EAE}$ & & & $\begin{array}{l}\uparrow \text { Apoptosis of astrocytes } \\
\uparrow \text { CD4/CD8 T cells } \\
\uparrow \text { IL-I7, IFN- } \gamma, \text { TNF }\end{array}$ & $\uparrow$ Demyelination & $\begin{array}{l}\text { (Haroon and others } \\
20 \mathrm{II})\end{array}$ \\
\hline SIprl & $\mathrm{EAE}$ & $\begin{array}{l}\text { GFAP-Cre- } \\
\text { SIpr| IoxP/loxP }\end{array}$ & - & $\downarrow$ Astrogliosis & $\begin{array}{l}\downarrow \text { EAE scores } \\
\downarrow \text { Axonal loss } \\
\downarrow \text { Demyelination }\end{array}$ & (Choi and others 20II) \\
\hline \multirow[t]{2}{*}{ TGF $\beta$} & dMCAO & $\begin{array}{l}\text { Ast-Tbr2DN } \\
\text { TGF } \beta \text { inhibited } \\
\text { specifically in }\end{array}$ & - & $\begin{array}{l}\downarrow \text { TGF } \beta-I \text { signaling } \\
\uparrow \text { Neuroinflammation } \\
\uparrow \text { CDI Ib }+ \text { and CD68+ }\end{array}$ & $\begin{array}{l}\downarrow \text { Brain preservation } \\
\uparrow \text { Motor impairments } \\
\uparrow \text { infarct expansion }\end{array}$ & $\begin{array}{l}\text { (Cekanaviciute and } \\
\text { others 20I4b) }\end{array}$ \\
\hline & TE & astrocytes & & $\begin{array}{l}\uparrow \text { Immune cell infiltration } \\
\uparrow \text { Astrocytes activation } \\
\uparrow \text { Myeloid cells activation } \\
\uparrow \text { NFkB activation }\end{array}$ & $\begin{array}{l}\downarrow \text { Parasite control } \\
\uparrow \text { Neuronal injury }\end{array}$ & $\begin{array}{l}\text { (Cekanaviciute and } \\
\text { others 2014a) }\end{array}$ \\
\hline GDNF & $\begin{array}{l}\text { Aging }(22 \\
\text { mo) }\end{array}$ & $\begin{array}{l}\text { Lenti-GDNF } \\
\text { Lenti-GFP }\end{array}$ & + & $\begin{array}{l}\uparrow \text { Acetylcholine, dopamine } \\
\text { and serotonin }\end{array}$ & $\uparrow$ Cognitive abilities & $\begin{array}{l}\text { (Pertusa and others } \\
\text { 2008) }\end{array}$ \\
\hline
\end{tabular}

$\mathrm{TE}=$ toxoplasma encephalitis; $\mathrm{EAE}=$ experimental autoimmune encephalomyelitis; $\mathrm{SCl}=$ spinal cord injury; WMI = white matter injury; $\mathrm{Cprz}$ = cuprizone; $3 \times \operatorname{TgAD} / 5 \times \mathrm{FAD}=$ Alzheimer's disease model; Htt82Q = Huntington disease model; dMCAO = distal middle cerebral artery occlusion. $\Delta$ indicates whether the pathway in question was manipulated upwards or downwards. 


\section{Phenotype Is Shaped By Multiple Signaling Pathways}

There is clear evidence for influences of STAT3, NFкB, NFAT, MAPK, Nrf2, Notch, and other signaling pathways on astrocyte phenotype in various conditions, and it seems reasonable to propose that the observed phenotype of astrocytes will be a product of the signaling pathways that are active in unison or in sequence (Fig. 4). STAT3 is directly implicated in driving reactive astrocytosis (Herrmann and others 2008) and is also activated in chronic neurodegeneration: the mSOD1 ALS model (Shibata and others 2009), the $3 \times \mathrm{Tg}$ AD model, and a lentiviral vectorbased non-human primate Huntington's disease model (Ben Haim and others 2015). Stat 3 is known to be induced by IL-6, IFN $\gamma$ and several growth factors and has multiple impacts on astrocyte phenotype (Ceyzériat and others 2016). Overexpression of the endogenous inhibitor of STAT3, SOCS3, was sufficient to prevent astrocyte reactivity in these models (Ben Haim and others 2015). However, while there is clearly NFKB activation driving the strongly pro-inflammatory changes observed in acute LPS and MCAO-treated animals (Zamanian and others 2012), there was not consistent evidence of NFKB nuclear localization in chronic ME7 or APP/PS1 models prior to the subsequent addition of IL- $1 \beta$ or TNF- $\alpha$ (Hennessy and others 2015; Lopez-Rodriguez and others 2018) and no suppression of IкB $\alpha$ in the $3 x T g$ or primate HD models (Ben Haim and others 2015). This suggests limited activation of NFKB during astrocytosis in chronic neurodegeneration, consistent with the failure of astrocyte $\mathrm{NF \kappa B}$ suppression to alter onset and progression in ALS (Crosio and others 2011). Therefore, we propose that STAT3 is active, and produces reactive astrocytosis across a broad range of insults, but that NFKB is less universal and its activation, upon subsequent stimuli, may facilitate another, more pro-inflammatory level of activation of these astrocytes, driving an additional panel of NFкB-dependent genes (Fig. 4). It is abundantly clear that $\mathrm{NF \kappa B}$ signaling in astrocytes has significant deleterious effects in multiple models of pathology (Brambilla and others 2005; Brambilla and others 2009b), but NFкB-dependent genes such as PTX3 are also important to glial scarring (RodriguezGrande and others 2014) and contribute to lesion restriction and improved recovery (Burda and Sofroniew 2014). The impact of suppressing astrocyte NFкB is, therefore, likely to be context and timing dependent.

There are also obviously several other signaling pathways that will further shape astrocyte phenotype. TGF $\beta 1$ is known to suppress activation of $\mathrm{NF \kappa B}$, making it an important candidate to limit NFkB-induced damage. TGF $\beta 1$ was found to be neuroprotective against $A \beta$ oligomer-induced synapse loss (Pereira Diniz and others 2017) and its deletion in astrocytes (Ast-Tbr2DN mice) increased severity of gliosis and inflammation in stroke and Toxoplasma infection (Cekanaviciute and others 2014b). However, its activation is not uniformly advantageous: astrocyte TGF $\beta 1$ activates MAP kinases and has been shown to contribute to ALS disease progression via suppression of T-cell IFN $\gamma$ and microglial modulation (Endo and others 2015).

S1P is a bioactive sphingolipid that acts via receptors $\mathrm{S} 1 \mathrm{P} 1-5$. Among these, the S1pr3 transcript is upregulated in most studies of astrocytosis and is regarded as a panreactive transcript (Liddelow and others 2017). S1P3 activation is known to drive $\mathrm{pERK}$, pAKT activation, and $\mathrm{Ca}^{2+}$ elevation (O'Sullivan and Dev 2017), which can further activate calcineurin and NFAT signaling. NFAT is an important pro-inflammatory transcription factor in its own right, elevated in aging and $\mathrm{AD}$ models and driving expression of C3, S100B, growth factors, cytokines, and chemokines (Sama and others 2008; Shirakawa and others 2017; Sompol and others 2017). The S1P modulating drug fingolimod (FTY720) can suppress many of these pro-inflammatory molecules (Rothhammer and others 2017) and astrocyte-specific deletion of S1P1 reduced demyelination and axonal loss in EAE (Choi and others 2011). S1P activation can contribute to the ability of IL-1 to trigger robust $\mathrm{NF \kappa B}$ activation (Colombo and others 2014). Therefore, disease-associated S1pr 3 elevation and S1P signaling may synergize with IL-1, or indeed TNF $\alpha$, to produce the exaggerated responses typical of primed astrocytes in the degenerating brain.

Among all these upregulated pathways, an important influence is the maintenance of Notch signaling by proximity to healthy neurons. The loss of this influence during neurodegeneration brings loss of Notch-regulated genes and diminished support for neuronal metabolism (Hasel and others 2017) and this may be an early step in facilitating a broad spectrum of astrocyte phenotypes (Fig. 4).

Recent studies have significantly broadened the range of molecules manipulated in astrocytosis in various pathological states, and although a full discussion of these is beyond the scope of this review, a small selection of these is provided in Figure 4 and Table 1. This list is not exhaustive (see Colombo and Farina, 2016, for review). Activation or suppression of these, and other, signaling pathways in various combinations is likely to underpin multiple astrocyte phenotypes.

\section{Concluding Remarks}

Systematic dissection of the relative contributions of different signaling pathways and different downstream mediators of their effects will be required to more fully appreciate the multiple states that astrocytes may adopt during CNS pathology. It will be necessary to fully dissect the impact of sequential or combinatorial activation 
where multiple signaling pathways become activated. Manipulation of astrocyte phenotype holds significant therapeutic potential, but it bears repeating that phenotypic diversity is determined by development and regionality and by dynamic changes to what these cells are exposed to during pathology. In both cases we must confront this heterogeneity to understand how astrocyte function shapes function and dysfunction in the brain.

\section{Declaration of Conflicting Interests}

The author(s) declared no potential conflicts of interest with respect to the research, authorship, and/or publication of this article.

\section{Funding}

The author(s) received no financial support for the research, authorship, and/or publication of this article.

\section{ORCID iDs}

Colm Cunningham (iD) https://orcid.org/0000-0003-1423-5209 Ana Belen Lopez-Rodriguez (iD) https://orcid.org/0000-0002 $-0747-7966$

\section{References}

Abbott NJ. 2002. Astrocyte-endothelial interactions and bloodbrain barrier permeability. J Anat 200:629-38. doi:10.1046/ J.1469-7580.2002.00064.X

Alvarez JI, Katayama T, Prat A. 2013. Glial influence on the blood brain barrier. Glia 61:1939-58. doi:10.1002/ glia. 22575

Anderson MA, Burda JE, Ren Y, Ao Y, O'Shea TM, Kawaguchi $\mathrm{R}$, and others. 2016. Astrocyte scar formation aids central nervous system axon regeneration. Nature 532:195-200. doi:10.1038/nature 17623

Andriezen WL. 1893. The neuroglia elements in the human brain. Br Med J 2:227-30.

Araque A, Parpura V, Sanzgiri RP, Haydon PG. 1999. Tripartite synapses: glia, the unacknowledged partner. Trends Neurosci 22:208-15. doi:10.1016/S01662236(98)01349-6

Babcock AA, Kuziel WA, Rivest S, Owens T. 2003. Chemokine expression by glial cells directs leukocytes to sites of axonal injury in the CNS. J Neurosci 23:7922-30. doi:10.1523/ JNEUROSCI.23-21-07922.2003

Bachoo RM, Kim RS, Ligon KL, Maher EA, Brennan C, Billings $\mathrm{N}$, and others. 2004. Molecular diversity of astrocytes with implications for neurological disorders. Proc Natl Acad Sci U S A 101(22):8384-9. doi:10.1073/pnas.0402140101

Barbierato M, Facci L, Argentini C, Marinelli C, Skaper SD, Giusti P. 2013. Astrocyte-microglia cooperation in the expression of a pro-inflammatory phenotype. CNS Neurol Disord Drug Targets 12:608-18. doi:10.2174/18715273113129990064

Ben Haim L, Ceyzeriat K, Carrillo-de Sauvage MA, Aubry F, Auregan G, Guillermier M, and others. 2015. The JAK/ STAT3 pathway is a common inducer of astrocyte reactivity in Alzheimer's and Huntington's diseases. J Neurosci 35:2817-29. doi:10.1523/JNEUROSCI.3516-14.2015
Ben Haim L, Rowitch DH. 2017. Functional diversity of astrocytes in neural circuit regulation. Nat Rev Neurosci 18:3141. doi:10.1038/nrn.2016.159

Biesmans S, Acton PD, Cotto C, Langlois X, Ver Donck L, Bouwknecht JA, and others. 2015. Effect of stress and peripheral immune activation on astrocyte activation in transgenic bioluminescent Gfap-luc mice. Glia 63:112637. doi:10.1002/glia.22804

Boisvert MM, Erikson GA, Shokhirev MN, Allen NJ. 2018. The aging astrocyte transcriptome from multiple regions of the mouse brain. Cell Rep 22:269-85. doi:10.1016/j.celrep.2017.12.039

Boulay AC, Mazeraud A, Cisternino S, Saubamea B, Mailly P, Jourdren L, and others. 2015. Immune quiescence of the brain is set by astroglial connexin 43. J Neurosci 35:442739. doi:10.1523/JNEUROSCI.2575-14.2015

Brambilla R, Bracchi-Ricard V, Hu WH, Frydel B, Bramwell A, Karmally S, and others. 2005. Inhibition of astroglial nuclear factor kappaB reduces inflammation and improves functional recovery after spinal cord injury. J Exp Med 202:145-56. doi:10.1084/jem.20041918

Brambilla R, Dvoriantchikova G, Barakat D, Ivanov D, Bethea JR, Shestopalov VI. 2012. Transgenic inhibition of astroglial NF- $\mathrm{NB}$ protects from optic nerve damage and retinal ganglion cell loss in experimental optic neuritis. J Neuroinflammation 9:213. doi:10.1186/1742-20949-213

Brambilla R, Hurtado A, Persaud T, Esham K, Pearse DD, Oudega M, and others. 2009a. Transgenic inhibition of astroglial NF-kappa B leads to increased axonal sparing and sprouting following spinal cord injury. J Neurochem 110:765-78. doi:10.1111/j.1471-4159.2009.06190.x

Brambilla R, Morton PD, Ashbaugh JJ, Karmally S, Lambertsen KL, Bethea JR. 2014. Astrocytes play a key role in EAE pathophysiology by orchestrating in the CNS the inflammatory response of resident and peripheral immune cells and by suppressing remyelination. Glia 62:452-67. doi:10.1002/ glia.22616

Brambilla R, Persaud T, Hu X, Karmally S, Shestopalov VI, Dvoriantchikova G, and others. 2009b. Transgenic inhibition of astroglial NF-kappa B improves functional outcome in experimental autoimmune encephalomyelitis by suppressing chronic central nervous system inflammation. J Immunol 182:2628-40. doi:10.4049/jimmunol.0802954

Bribián A, Figueres-Oñate M, Martín-López E, LópezMascaraque L. 2016. Decoding astrocyte heterogeneity: new tools for clonal analysis. Neuroscience 323:10-9. doi:10.1016/j.neuroscience.2015.04.036

Bringmann A, Pannicke T, Biedermann B, Francke M, Iandiev I, Grosche J, and others. 2009. Role of retinal glial cells in neurotransmitter uptake and metabolism. Neurochem Int 54:143-60. doi:10.1016/j.neuint.2008.10.014

Brosnan CF, Raine CS. 2013. The astrocyte in multiple sclerosis revisited. Glia 61:453-65. doi:10.1002/glia.22443

Burda JE, Sofroniew M V. 2014. Reactive gliosis and the multicellular response to CNS damage and disease. Neuron 81:229-48. doi:10.1016/j.neuron.2013.12.034

Butchi NB, Du M, Peterson KE. 2010. Interactions between TLR7 and TLR9 agonists and receptors regulate innate 
immune responses by astrocytes and microglia. Glia 58:650-64. doi:10.1002/glia.20952

Cahoy JD, Emery B, Kaushal A, Foo LC, Zamanian JL, Christopherson KS, and others. 2008. A transcriptome database for astrocytes, neurons, and oligodendrocytes: a new resource for understanding brain development and function. J Neurosci 28:264-78. doi:10.1523/ JNEUROSCI.4178-07.2008

Cekanaviciute E, Dietrich HK, Axtell RC, Williams AM, Egusquiza R, Wai KM, and others. 2014a. Astrocytic TGF$\beta$ signaling limits inflammation and reduces neuronal damage during central nervous system Toxoplasma infection. J Immunol 193:139-49. doi:10.4049/jimmunol.1303284

Cekanaviciute E, Fathali N, Doyle KP, Williams AM, Han J, Buckwalter MS. 2014b. Astrocytic transforming growth factor-beta signaling reduces subacute neuroinflammation after stroke in mice. Glia 62:1227-40. doi:10.1002/ glia. 22675

Ceyzériat K, Abjean L, Carrillo-de Sauvage MA, Ben Haim L, Escartin C. 2016. The complex STATes of astrocyte reactivity: how are they controlled by the JAK-STAT3 pathway? Neuroscience 330:205-18. doi:10.1016/j.neuroscience.2016.05.043

Chaboub LS, Deneen B. 2012. Developmental origins of astrocyte heterogeneity: the final frontier of CNS development. Dev Neurosci 34(5):379-88. doi:10.1159/000343723

Chai H, Diaz-Castro B, Shigetomi E, Monte E, Octeau JC, Yu X, and others. 2017. Neural circuit-specialized astrocytes: transcriptomic, proteomic, morphological, and functional evidence. Neuron 95(3):531-49.e9. doi:10.1016/j.neuron.2017.06.029

Chaigneau E, Oheim M, Audinat E, Charpak S. 2003. Twophoton imaging of capillary blood flow in olfactory bulb glomeruli. Proc Natl Acad Sci U S A 100:13081-6. doi:10.1073/pnas.2133652100

Chen Q, Sun L, Chen ZJ. 2016. Regulation and function of the cGAS-STING pathway of cytosolic DNA sensing. Nat Immunol 17(10):1142-9. doi:10.1038/ni.3558

Chih CP, Roberts EL. 2003. Energy substrates for neurons during neural activity: a critical review of the astrocyte-neuron lactate shuttle hypothesis. J Cereb Blood Flow Metab 23:1263-81. doi:10.1097/01.WCB.0000081369.51727.6F

Choi JW, Gardell SE, Herr DR, Rivera R, Lee CW, Noguchi K, and others. 2011 . FTY720 (fingolimod) efficacy in an animal model of multiple sclerosis requires astrocyte sphingosine 1-phosphate receptor 1 (S1P1) modulation. Proc Natl Acad Sci U S A 108:751-6. doi:10.1073/pnas.1014154108

Choi SS, Lee HJ, Lim I, Satoh J, Kim SU. 2014. Human astrocytes: secretome profiles of cytokines and chemokines. PLoS One 9(4):e92325. doi:10.1371/journal.pone.0092325

Chow KT, Gale M, Loo YM. 2018. RIG-I and other RNA sensors in antiviral immunity. Annu Rev Immunol 36:667-94. doi:10.1146/annurev-immunol-042617-053309

Chung IY, Benveniste EN. 1990. Tumor necrosis factor-alpha production by astrocytes. Induction by lipopolysaccharide, IFN-gamma, and IL-1 beta. J Immunol 144(8):2999-3007.

Chung WS, Clarke LE, Wang GX, Stafford BK, Sher A, Chakraborty C, and others. 2013. Astrocytes mediate synapse elimination through MEGF10 and MERTK pathways. Nature 504:394-400. doi:10.1038/nature12776
Clarke LE, Liddelow SA, Chakraborty C, Münch AE, Heiman M, Barres BA. 2018. Normal aging induces A1-like astrocyte reactivity. Proc Natl Acad Sci U S A 115(8):E1896905. doi:10.1073/pnas.1800165115

Colombo E, Di Dario M, Capitolo E, Chaabane L, Newcombe J, Martino G, and others. 2014. Fingolimod may support neuroprotection via blockade of astrocyte nitric oxide. Ann Neurol 76:325-37. doi:10.1002/ana.24217

Colombo E, Farina C. 2016. Astrocytes: key regulators of neuroinflammation. Trends Immunol 37:608-20. doi:10.1016/j. it.2016.06.006

Cox DJ, Field RH, Williams DG, Baran M, Bowie AG, Cunningham C, and others. 2015. DNA sensors are expressed in astrocytes and microglia in vitro and are upregulated during gliosis in neurodegenerative disease. Glia 63(5):812-25. doi:10.1002/glia.22786

Crosio C, Valle C, Casciati A, Iaccarino C, Carrì MT. 2011. Astroglial inhibition of NF- $\mathrm{KB}$ does not ameliorate disease onset and progression in a mouse model for amyotrophic lateral sclerosis (ALS). PLoS One 6:e17187. doi:10.1371/ journal.pone. 0017187

Cunningham C, Deacon R, Wells H, Boche D, Waters S, Diniz CP, and others. 2003. Synaptic changes characterize early behavioural signs in the ME7 model of murine prion disease. Eur J Neurosci 17:2147-55.

Cunningham C, Wilcockson DC, Campion S, Lunnon K, Perry VH. 2005. Central and systemic endotoxin challenges exacerbate the local inflammatory response and increase neuronal death during chronic neurodegeneration. J Neurosci 25:9275-84. doi:10.1523/ JNEUROSCI.2614-05.2005

De Miranda J, Yaddanapudi K, Hornig M, Lipkin WI. 2008. Astrocytes recognize intracellular polyinosinic-polycytidylic acid via MDA-5. FASEB J 23:1064-71. doi:10.1096/ fj.08-121434

Deneen B, Ho R, Lukaszewicz A, Hochstim CJ, Gronostajski RM, Anderson DJ. 2006. The transcription factor NFIA controls the onset of gliogenesis in the developing spinal cord Neuron 52:953-68. doi:10.1016/j.neuron.2006.11.019

Dhanwani R, Takahashi M, Sharma S. 2018. Cytosolic sensing of immuno-stimulatory DNA, the enemy within. Curr Opin Immunol 50:82-7. doi:10.1016/j.coi.2017.11.004

Doyle JP, Dougherty JD, Heiman M, Schmidt EF, Stevens TR, Ma G, and others. 2008. Application of a translational profiling approach for the comparative analysis of CNS cell types. Cell 135:749-62. doi:10.1016/j. cell.2008.10.029

Drögemüller K, Helmuth U, Brunn A, Sakowicz-Burkiewicz M, Gutmann DH, Mueller W, and others. 2008. Astrocyte gp130 expression is critical for the control of Toxoplasma encephalitis. J Immunol 181:2683-93.

Emsley JG, Macklis JD. 2006. Astroglial heterogeneity closely reflects the neuronal-defined anatomy of the adult murine CNS. Neuron Glia Biol 2:175-86. doi:10.1017/ S1740925X06000202

Endo Y, Asou HK, Tokuyama H, Yokote K, Correspondence TN. 2015. Obesity drives Th17 cell differentiation by inducing the lipid metabolic kinase, ACC1 accession numbers GSE70472. Cell Rep 12(6):1042-55. doi:10.1016/j. celrep.2015.07.014 
Facci L, Barbierato M, Marinelli C, Argentini C, Skaper SD, Giusti P. 2014. Toll-like receptors 2, -3 and -4 prime microglia but not astrocytes across central nervous system regions for ATP-dependent interleukin-1 $\beta$ Release. Sci Rep 4:6824. doi:10.1038/srep06824

Farina C, Aloisi F, Meinl E. 2007. Astrocytes are active players in cerebral innate immunity. Trends Immunol 28:138-45. doi:10.1016/j.it.2007.01.005

Farmer WT, Abrahamsson T, Chierzi S, Lui C, Zaelzer C, Jones EV, and others. 2016. Neurons diversify astrocytes in the adult brain through sonic hedgehog signaling. Science 351(6275):849-54. doi:10.1126/science.aab3103

Fernandez AM, Fernandez S, Carrero P, Garcia-Garcia M, Torres-Aleman I. 2007. Calcineurin in reactive astrocytes plays a key role in the interplay between proinflammatory and anti-inflammatory signals. J Neurosci 27:8745-56. doi:10.1523/JNEUROSCI.1002-07.2007

Fierz W, Endler B, Reske K, Wekerle H, Fontana A. 1985. Astrocytes as antigen-presenting cells. I. Induction of Ia antigen expression on astrocytes by $\mathrm{T}$ cells via immune interferon and its effect on antigen presentation. J Immunol 134:3785-93.

Furman JL, Sama DM, Gant JC, Beckett TL, Murphy MP, Bachstetter AD, and others. 2012. Targeting astrocytes ameliorates neurologic changes in a mouse model of Alzheimer's disease. J Neurosci 32:16129-40. doi:10.1523/ JNEUROSCI.2323-12.2012

Furr SR, Chauhan VS, Sterka D, Grdzelishvili V, Marriott I. 2008. Characterization of retinoic acid-inducible geneI expression in primary murine glia following exposure to vesicular stomatitis virus. J Neurovirol 14:503-13. doi:10.1080/13550280802337217

Gao D, Li T, Li XD, Chen X, Li QZ, Wight-Carter M and others. 2015. Activation of cyclic GMP-AMP synthase by selfDNA causes autoimmune diseases. Proc Natl Acad Sci U S A 112(42):E5699-705. doi:10.1073/pnas.1516465112

García-Cáceres C, Quarta C, Varela L, Gao Y, Gruber T, Legutko B, and others. 2016. Astrocytic insulin signaling couples brain glucose uptake with nutrient availability. Cell 166:867-80. doi:10.1016/j.cell.2016.07.028

Gomez-Arboledas A, Davila JC, Sanchez-Mejias E, Navarro V, Nuñez-Diaz C, Sanchez-Varo R, and others. 2018. Phagocytic clearance of presynaptic dystrophies by reactive astrocytes in Alzheimer's disease. Glia 66:637-53. doi:10.1002/glia.23270

Gray EE, Treuting PM, Woodward JJ, Stetson DB. 2015. Cutting edge: cGAS is required for lethal autoimmune disease in the trex1-deficient mouse model of Aicardi-Goutières syndrome. J Immunol 195(5):1939-43. doi:10.4049/jimmunol.1500969

Halassa MM, Florian C, Fellin T, Munoz JR, Lee SY, Abel T, and others. 2009. Astrocytic modulation of sleep homeostasis and cognitive consequences of sleep loss. Neuron 61:213-9. doi:10.1016/j.neuron.2008.11.024

Halassa MM, Haydon PG. 2010. Integrated brain circuits: astrocytic networks modulate neuronal activity and behavior. Annu Rev Physiol 72:335-55. doi:10.1146/annurevphysiol-021909-135843

Hamby ME, Coppola G, Ao Y, Geschwind DH, Khakh BS, Sofroniew MV. 2012. Inflammatory mediators alter the astrocyte transcriptome and calcium signaling elicited by multiple G-protein-coupled receptors. J Neurosci 32:14489-510. doi:10.1523/JNEUROSCI.1256-12.2012

Haroon F, Drögemüller K, Händel U, Brunn A, Reinhold D, Nishanth G, and others. 2011. Gp130-dependent astrocytic survival is critical for the control of autoimmune central nervous system inflammation. J Immunol 186:6521-31. doi:10.4049/jimmunol.1001135

Hasegawa-Ishii S, Inaba M, Umegaki H, Unno K, Wakabayashi K, Shimada A. 2016. Endotoxemia-induced cytokinemediated responses of hippocampal astrocytes transmitted by cells of the brain-immune interface. Sci Rep 6:25457. doi:10.1038/srep25457

Hasel P, Dando O, Jiwaji Z, Baxter P, Todd AC, Heron S, and others. 2017. Neurons and neuronal activity control gene expression in astrocytes to regulate their development and metabolism. Nat Commun 8:15132. doi:10.1038/ ncomms 15132

Henn A, Kirner S, Leist M. 2011. TLR2 hypersensitivity of astrocytes as functional consequence of previous inflammatory episodes. J Immunol 186:3237-47. doi:10.4049/ jimmunol.1002787

Hennessy E, Griffin ÉW, Cunningham C. 2015. Astrocytes are primed by chronic neurodegeneration to produce exaggerated chemokine and cell infiltration responses to acute stimulation with the cytokines IL- $1 \beta$ and TNF- $\alpha$. J Neurosci 35:8411-22. doi:10.1523/JNEUROSCI.2745-14.2015

Herrmann JE, Imura T, Song B, Qi J, Ao Y, Nguyen TK, and others. 2008. STAT3 is a critical regulator of astrogliosis and scar formation after spinal cord injury. J Neurosci 28:7231-43. doi:10.1523/JNEUROSCI.1709-08.2008

Hindinger C, Bergmann CC, Hinton DR, Phares TW, Parra GI, Hussain S, and others. 2012. IFN- $\gamma$ signaling to astrocytes protects from autoimmune mediated neurological disability. PLoS One 7(7):e42088. doi:10.1371/journal. pone. 0042088

Holm TH, Draeby D, Owens T. 2012. Microglia are required for astroglial toll-like receptor 4 response and for optimal TLR2 and TLR3 response. Glia 60:630-8. doi:10.1002/ glia.22296

Holtman IR, Raj DD, Miller JA, Schaafsma W, Yin Z, Brouwer $\mathrm{N}$, and others. 2015. Induction of a common microglia gene expression signature by aging and neurodegenerative conditions: a co-expression meta-analysis. Acta Neuropathol Commun 3:31. doi:10.1186/s40478-015-0203-5

Hoogland TM, Kuhn B. 2010. Recent developments in the understanding of astrocyte function in the cerebellum in vivo. Cerebellum 9:264-71. doi:10.1007/s12311-009-0139-Z

Iram T, Ramirez-Ortiz Z, Byrne MH, Coleman UA, Kingery ND, Means TK, and others. 2016. Megf10 Is a receptor for C1Q that mediates clearance of apoptotic cells by astrocytes. J Neurosci 36:5185-92. doi:10.1523/ JNEUROSCI.3850-15.2016

Jeffries AM, Marriott I. 2017. Human microglia and astrocytes express cGAS-STING viral sensing components. Neurosci Lett 658:53-6. doi:10.1016/j.neulet.2017.08.039

John GR, Lee SC, Song X, Rivieccio M, Brosnan CF. 2005. IL-1-regulated responses in astrocytes: relevance to injury and recovery. Glia 49:161-76. doi:10.1002/glia.20109

Jones RS, Minogue AM, Connor TJ, Lynch MA. 2013. Amyloid- $\beta$-induced astrocytic phagocytosis is mediated 
by CD36, CD47 and RAGE. J Neuroimmune Pharmacol 8:301-11. doi:10.1007/s11481-012-9427-3

Khorooshi R, Owens T. 2010. Injury-induced type I IFN signaling regulates inflammatory responses in the central nervous system. J Immunol 185:1258-64. doi:10.4049/ jimmunol.0901753

Khorooshi R, Babcock AA, Owens T. 2008. NF-kappaB-driven STAT2 and CCL2 expression in astrocytes in response to brain injury. J Immunol 181(10):7284-91.

Kölliker A. 1889. Handbuch der Gewebelehre des Menschen. Leipzig, Germany.

Kraft AW, Hu X, Yoon H, Yan P, Xiao Q, Wang Y, and others. 2013. Attenuating astrocyte activation accelerates plaque pathogenesis in APP/PS1 mice. FASEB J 27:187-98. doi:10.1096/fj.12-208660

Kriegstein A, Alvarez-Buylla A. 2009. The glial nature of embryonic and adult neural stem cells. Annu Rev Neurosci 32:149-84. doi:10.1146/annurev.neuro.051508.135600

Lagos-Cabré R, Alvarez A, Kong M, Burgos-Bravo F, Cárdenas A, Rojas-Mancilla E, and others. 2017. $\alpha$ V 33 Integrin regulates astrocyte reactivity. J Neuroinflammation 14:194. doi:10.1186/s12974-017-0968-5

Li L, Lundkvist A, Andersson D, Wilhelmsson U, Nagai N, Pardo AC, and others. 2008. Protective role of reactive astrocytes in brain ischemia. J Cereb Blood Flow Metab 28:468-81. doi:10.1038/sj.jcbfm.9600546

Liddelow SA, Barres BA. 2017. Reactive astrocytes: production, function, and therapeutic potential. Immunity 46:95767. doi:10.1016/j.immuni.2017.06.006

Liddelow SA, Guttenplan KA, Clarke LE, Bennett FC, Bohlen CJ, Schirmer L, and others. 2017. Neurotoxic reactive astrocytes are induced by activated microglia. Nature 541:481-7. doi:10.1038/nature21029

Lopez-Rodriguez AB, Hennessy E, Murray C, Lewis A, De Barra N, Fagan S and others. 2018. Microglial and Astrocyte priming in the APP/PS1 model of Alzheimer's disease: increased vulnerability to acute inflammation and cognitive deficits. bioRxiv:344218. doi:10.1101/344218

Lovatt D, Sonnewald U, Waagepetersen HS, Schousboe A, He W, Lin JHC, and others. 2007. The transcriptome and metabolic gene signature of protoplasmic astrocytes in the adult murine cortex. J Neurosci 27:12255-66. doi:10.1523/ JNEUROSCI.3404-07.2007

Lundgaard I, Li B, Xie L, Kang H, Sanggaard S, Haswell JDR, and others. 2015. Direct neuronal glucose uptake heralds activity-dependent increases in cerebral metabolism. Nat Commun 6:6807. doi:10.1038/ncomms 7807

Mächler P, Wyss MT, Elsayed M, Stobart J, Gutierrez R, von Faber-Castell A, and others. 2016. In vivo evidence for a lactate gradient from astrocytes to neurons. Cell Metab 23:94-102. doi:10.1016/j.cmet.2015.10.010

MacVicar BA, Newman EA. 2015. Astrocyte regulation of blood flow in the brain. Cold Spring Harb Perspect Biol 7(5). doi:10.1101/cshperspect.a020388

Magistretti PJ, Pellerin L. 1996. Cellular bases of brain energy metabolism and their relevance to functional brain imaging: evidence for a prominent role of astrocytes. Cereb Cortex 6:50-61.
Morel L, Chiang MSR, Higashimori H, Shoneye T, Iyer LK, Yelick J, and others. 2017. Molecular and functional properties of regional astrocytes in the adult brain. J Neurosci 37:8706-17. doi:10.1523/JNEUROSCI.3956-16.2017

Morizawa YM, Hirayama Y, Ohno N, Shibata S, Shigetomi E, Sui Y, and others. 2017. Reactive astrocytes function as phagocytes after brain ischemia via ABCA1-mediated pathway. Nat Commun 8:28. doi:10.1038/s41467-017-00037-1

Nimmerjahn A, Kirchhoff F, Helmchen F. 2005. Resting microglial cells are highly dynamic surveillants of brain parenchyma in vivo. Science 308:1314-8. doi:10.1126/science. 1110647

Nobuta H, Ghiani CA, Paez PM, Spreuer V, Dong H, Korsak RA, and others. 2012. STAT3-mediated astrogliosis protects myelin development in neonatal brain injury. Ann Neurol 72:750-65. doi:10.1002/ana.23670

Norden DM, Trojanowski PJ, Villanueva E, Navarro E, Godbout JP. 2016. Sequential activation of microglia and astrocyte cytokine expression precedes increased iba-1 or GFAP immunoreactivity following systemic immune challenge. Glia 64:300-16. doi:10.1002/glia.22930

Noristani HN, Sabourin JC, Boukhaddaoui H, Chan-Seng E, Gerber YN, Perrin FE. 2016. Spinal cord injury induces astroglial conversion towards neuronal lineage. Mol Neurodegener 11:68. doi:10.1186/s13024-016-0133-0

Okada S, Nakamura M, Katoh H, Miyao T, Shimazaki T, Ishii $\mathrm{K}$, and others. 2006. Conditional ablation of Stat3 or Socs3 discloses a dual role for reactive astrocytes after spinal cord injury. Nat Med 12:829-34. doi:10.1038/nm1425

Oliveira JF, Sardinha VM, Guerra-Gomes S, Araque A, Sousa N. 2015. Do stars govern our actions? Astrocyte involvement in rodent behavior. Trends Neurosci 38:535-49. doi:10.1016/j.tins.2015.07.006

Orellana JA, Stehberg J. 2014. Hemichannels: new roles in astroglial function. Front Physiol 5:193. doi:10.3389/ fphys.2014.00193

Orre M, Kamphuis W, Osborn LM, Jansen AHPP, Kooijman L, Bossers K and others. 2014. Isolation of glia from Alzheimer's mice reveals inflammation and dysfunction. Neurobiol Aging 35:2746-60. doi:10.1016/j.neurobiolaging.2014.06.004

O'Sullivan S, Dev KK. 2017. Sphingosine-1-phosphate receptor therapies: advances in clinical trials for CNS-related diseases. Neuropharmacology 113:597-607. doi:10.1016/j. neuropharm.2016.11.006

Paolicelli RC, Bergamini G, Rajendran L. 2018. Cell-to-cell communication by extracellular vesicles: focus on microglia. Neuroscience. doi:10.1016/J.NEUROSCIENCE.2018.04.003

Pereira Diniz L, Tortelli V, Matias I, Morgado J, Bérgamo Araujo AP, Melo HM, and others. 2017. Astrocyte transforming growth factor beta 1 protects synapses against $\mathrm{A} \beta$ oligomers in Alzheimer's disease model. J Neurosci 37:6797-809. doi:10.1523/JNEUROSCI.3351-16.2017

Pertusa M, García-Matas S, Mammeri H, Adell A, Rodrigo T, Mallet J, and others. 2008. Expression of GDNF transgene in astrocytes improves cognitive deficits in aged rats. Neurobiol Aging 29:1366-79. doi:10.1016/j.neurobiolaging.2007.02.026 
Place DE, Kanneganti TD. 2018. Recent advances in inflammasome biology. Curr Opin Immunol 50:32-8. doi:10.1016/j. coi.2017.10.011

Ponath G, Ramanan S, Mubarak M, Housley W, Lee S, Sahinkaya FR, and others. 2017. Myelin phagocytosis by astrocytes after myelin damage promotes lesion pathology. Brain 140:399-413. doi:10.1093/brain/aww298

Quintas C, Vale N, Gonçalves J, Queiroz G. 2018. Microglia $\mathrm{P} 2 \mathrm{Y} 13$ receptors prevent astrocyte proliferation mediated by P2Y1 receptors. Front Pharmacol 9:418. doi:10.3389/ fphar.2018.00418

Raasch J, Zeller N, van Loo G, Merkler D, Mildner A, Erny $\mathrm{D}$, and others. 2011. IkappaB kinase 2 determines oligodendrocyte loss by non-cell-autonomous activation of NF-kappaB in the central nervous system. Brain 134:118498. doi:10.1093/brain/awq359

Ramón y, Cajal S. 1995. Histology of the nervous system of man and vertebrates. Oxford: Oxford University Press.

Reinert LS, Lopušná K, Winther H, Sun C, Thomsen MK, Nandakumar R, and others. 2016. Sensing of HSV-1 by the cGAS-STING pathway in microglia orchestrates antiviral defence in the CNS. Nat Commun 7:13348. doi:10.1038/ ncomms 13348

Rodriguez-Grande B, Swana M, Nguyen L, Englezou P, Maysami S, Allan SM, and others. 2014. The acute-phase protein PTX3 is an essential mediator of glial scar formation and resolution of brain edema after ischemic injury. J Cereb Blood Flow Metab 34:480-8. doi:10.1038/jcbfm.2013.224

Rothhammer V, Kenison JE, Tjon E, Takenaka MC, de Lima KA, Borucki DM, and others. 2017. Sphingosine 1-phosphate receptor modulation suppresses pathogenic astrocyte activation and chronic progressive CNS inflammation. Proc Natl Acad Sci U S A 114(8):2012-7. doi:10.1073/ pnas. 1615413114

Sama MA, Mathis DM, Furman JL, Abdul HM, Artiushin IA, Kraner SD, Norris CM. 2008. Interleukin 1b-dependent signalling between astrocytes and neurons depends critically on astrocyte calcineurin/NFAT activity. J. Biol. Chem 283(32): 21953-64.

Saura J. 2007. Microglial cells in astroglial cultures: a cautionary note. J Neuroinflammation 4:26. doi:10.1186/1742-2094-4-26

Schleich CL. 1894. Schmerzlose Operationen. Oertliche Betäubung mit indifferenten Flüssigkeiten. Psychophysik des natürlichen und künstlichen Schlafes. Berlin: Springer.

Semmler A, Okulla T, Sastre M, Dumitrescu-Ozimek L, Heneka MT. 2005. Systemic inflammation induces apoptosis with variable vulnerability of different brain regions. J Chem Neuroanat 30:144-57. doi:10.1016/j.jchemneu.2005.07.003

Shi Y, Yamada K, Liddelow SA, Smith ST, Zhao L, Luo W, and others. 2017. ApoE4 markedly exacerbates tau-mediated neurodegeneration in a mouse model of tauopathy. Nature 549:523-7. doi:10.1038/nature24016

Shibata N, Yamamoto T, Hiroi A, Omi Y, Kato Y, Kobayashi M. 2009. Activation of STAT3 and inhibitory effects of pioglitazone on STAT3 activity in a mouse model of SOD1mutated amyotrophic lateral sclerosis. Neuropathology 30:353-60. doi:10.1111/j.1440-1789.2009.01078.x
Shirakawa H, Katsumoto R, Iida S, Miyake T, Higuchi T, Nagashima T, and others. 2017. Sphingosine-1-phosphate induces $\mathrm{Ca}^{2+}$ signaling and CXCL1 release via TRPC6 channel in astrocytes. Glia 65(6):1005-16. doi:10.1002/glia.23141

Sofroniew MV, Vinters HV. 2010. Astrocytes: biology and pathology. Acta Neuropathol 119:7-35. doi:10.1007/ s00401-009-0619-8

Sokoloff L. 1989. Circulation and energy metabolism of the brain. In: Siegel GJ, Agranoff BW, Albers RW, and others, editors. Basic neurochemistry: molecular, cellular and medical aspects. 6th ed. Philadelphia: Lippincott-Raven.

Sompol P, Furman JL, Pleiss MM, Kraner SD, Artiushin IA, Batten SR, and others. 2017. Calcineurin/NFAT signaling in activated astrocytes drives network hyperexcitability in A $\beta$-bearing mice. J Neurosci 37:6132-48. doi:10.1523/ JNEUROSCI.0877-17.2017

Stevens B, Allen NJ, Vazquez LE, Howell GR, Christopherson KS, Nouri N and others. 2007. The classical complement cascade mediates CNS synapse elimination. Cell 131:1164-78. doi:10.1016/j.cell.2007.10.036

Sun H, Liang R, Yang B, Zhou Y, Liu M, Fang F, and others. 2016. Aquaporin-4 mediates communication between astrocyte and microglia: implications of neuroinflammation in experimental Parkinson's disease. Neuroscience 317:65-75. doi:10.1016/j.neuroscience.2016.01.003

Tang BL. 2018. Brain activity-induced neuronal glucose uptake/ glycolysis: is the lactate shuttle not required? Brain Res Bull 137:225-8. doi:10.1016/j.brainresbull.2017.12.010

Verkhratsky A, Nedergaard M. 2014. Astroglial cradle in the life of the synapse. Philos Trans R Soc Lond B Biol Sci 369:20130595. doi:10.1098/rstb.2013.0595

Verkhratsky A, Nedergaard M. 2018. Physiology of astroglia. Physiol Rev 98:239-389. doi:10.1152/physrev.00042.2016

Virchow R. 1858. Die Cellularpathologie in ihrer Begründung auf physiologische und pathologische Gewebelehre. Zwanzig Vorlesungen gehalten während der Monate Februar, März und April 1959 im pathologischen Institut zu Berlin. Berlin: August Hirschwald.

Wang Y, Jin S, Sonobe Y, Cheng Y, Horiuchi H, Parajuli B, and others. 2014. Interleukin-1 $\beta$ induces blood-brain barrier disruption by downregulating Sonic hedgehog in astrocytes. PLoS One 9(10):e110024. doi:10.1371/journal.pone.0110024

Wanner IB, Anderson MA, Song B, Levine J, Fernandez A, Gray-Thompson Z, and others. 2013. Neurobiology of disease glial scar borders are formed by newly proliferated, elongated astrocytes that interact to corral inflammatory and fibrotic cells via STAT3-dependent mechanisms after spinal cord injury. J Neurosci 33(31):12870-86. doi:10.1523/ JNEUROSCI.2121-13.2013

Watanabe M, Masaki K, Yamasaki R, Kawanokuchi J, Takeuchi H, Matsushita T, and others. 2016. Th1 cells downregulate connexin 43 gap junctions in astrocytes via microglial activation. Sci Rep 6:38387. doi:10.1038/srep38387

Williams KC, Dooley NP, Ulvestad E, Waage A, Blain M, Yong VW, and others. 1995. Antigen presentation by human fetal astrocytes with the cooperative effect of microglia or the microglial-derived cytokine IL-1. J Neurosci 15: 1869-78. 
Wyss-Coray T, Loike JD, Brionne TC, Lu E, Anankov R, Yan F, and others. 2003. Adult mouse astrocytes degrade amyloid- $\beta$ in vitro and in situ. Nat Med 9:453-7. doi: $10.1038 / \mathrm{nm} 838$

Yan Y, Ding X, Li K, Ciric B, Wu S, Xu H, and others. 2012. CNS-specific therapy for ongoing EAE by silencing IL-17 pathway in astrocytes. Mol Ther 20:1338-48. doi:10.1038mt.2012.12

Yun SP, Kam TI, Panicker N, Kim S, Oh Y, Park JS, and others. 2018. Block of A1 astrocyte conversion by microglia is neuroprotective in models of Parkinson's disease. Nat Med 24:931-8. doi:10.1038/s41591-018-0051-5

Zamanian JL, Xu L, Foo LC, Nouri N, Zhou L, Giffard $\mathrm{RG}$, and others. 2012. Genomic analysis of reactive astrogliosis. J Neurosci 32:6391-410. doi:10.1523/ JNEUROSCI.6221-11.2012

Zeisel A, Hochgerner H, Lönnerberg P, Johnsson A, Memic F, van der Zwan J, and others. 2018. Molecular architecture of the mouse nervous system. Cell 174:999-1014.e22. doi:10.1016/j.cell.2018.06.021 